\title{
Investigating the impact of indoor temperature on the performance of the retail commercial refrigeration system
}

\author{
Oliver Brownbridge, Matthew Sully, Joshua Noons and Ibrahim M. Albayati*
}

\begin{abstract}
Commercial food outlets in the UK are responsible for 3\% of the UK total energy consumption, with refrigeration systems account for $29 \%$ of this total. In this paper, a validated model that simulates a commercial refrigeration system installed over 2000 sq. ft to mimic a real express store installed at the Riseholme Refrigeration Research Centre at the University of Lincoln, UK, is presented. Investigations are conducted to examine the different failures of air conditioning (AC) systems and their impacts on the indoor store temperature, and hence on the refrigeration performance and energy consumption. Three different scenarios were examined: gradual increase in store temperature caused by an AC system with reduced performance, sudden increase in store temperature caused by a drastic AC failure and fluctuations in store temperature caused by a faulty AC system. The results of the investigation for different failure scenarios of the $A C$ system during $3 \mathrm{~h}$ of continual operation showed an increase in the energy consumption of the refrigeration system by $17.4 \%$ as a result of gradual $\mathrm{AC}$ failure, $33.6 \%$ for the sudden failure and $5.3 \%$ for the intermittent failure. It is concluded that the AC failures caused the power drawn to increase due to spending a prolonged period of time at higher temperatures than during the normal AC operation. Also, the frequency which the compressors switch on and off increases the level of wear on the compressors. Both gradual and sudden failures of the AC system show a sustained increase in temperature that leads to a greater duty cycle for the expansion valve to increase the amount of refrigerant available. It is found that the sudden failure of the $\mathrm{AC}$ system had the greatest impact on the system, as the temperature of the store rises quickest, the display cases are exposed to higher temperatures for a longer time; this causes the greatest demand on the system and so lead to the largest power consumption. It is notable that for all three failure types that the product temperature experiences, there are no noticeable fluctuations and they remain comfortably within the temperature boundaries between 3 and $1{ }^{\circ} \mathrm{C}$, as the system is able to provide an adequate cooling.
\end{abstract}

Keywords: Modelling and simulation, Commercial refrigeration system, AC failure, Store temperature, Power consumption

* Correspondence: ialbayati@lincoln.ac.uk

College of Science, School of Engineering, University of Lincoln, Brayford

Pool, Lincoln LN6 7TS, UK

๑ The Author(s). 2022 Open Access This article is licensed under a Creative Commons Attribution 4.0 International License, which permits use, sharing, adaptation, distribution and reproduction in any medium or format, as long as you give appropriate credit to the original author(s) and the source, provide a link to the Creative Commons licence, and indicate if changes were made. The images or other third party material in this article are included in the article's Creative Commons licence, unless indicated otherwise in a credit line to the material. If material is not included in the article's Creative Commons licence and your intended use is not permitted by statutory regulation or exceeds the permitted use, you will need to obtain permission directly from the copyright holder. To view a copy of this licence, visit http://creativecommons.org/licenses/by/4.0/. 


\section{Nomenclature}

\begin{tabular}{|c|c|}
\hline Symbol & Parameter description \\
\hline$\overline{C_{p, i}}$ & $\begin{array}{l}\text { Specific heat capacity, where } i \text { denotes the media } \\
\text { which the parameter refers to }\end{array}$ \\
\hline CPT & Calculated product temperature \\
\hline$C_{V}$ & $\begin{array}{l}\text { Orifice coefficient or valve characterising constant } \\
\text { Collection of constants such as the cross-sectional } \\
\text { area of the valve inlet and outlet }\end{array}$ \\
\hline$h_{l g, \text { in }}$ & $\begin{array}{l}\text { Enthalpy of the refrigerant at the inlet of the } \\
\text { evaporator }\end{array}$ \\
\hline$h_{l g, \text { out }}$ & $\begin{array}{l}\text { Enthalpy of the refrigerant at the outlet of the } \\
\text { evaporator }\end{array}$ \\
\hline$k_{m}$ & $\begin{array}{l}\text { Ratio of mass of refrigerant in the evaporator to the } \\
\text { maximum capacity of the evaporator }\end{array}$ \\
\hline$m_{i}$ & $\begin{array}{l}\text { Mass, where } i \text { denotes the media which the } \\
\text { parameter refers to }\end{array}$ \\
\hline$m_{\text {ref }}$ & Mass of liquefied refrigerant in the evaporator \\
\hline$\dot{m}_{\mathrm{ref}, \mathrm{in}}$ & Mass flow rate of refrigerant into the evaporator \\
\hline$m_{\text {ref, } \max }$ & Maximum capacity of the evaporator \\
\hline$\dot{m}_{\text {ref,out }}$ & Mass flow rate of refrigerant out of the evaporator \\
\hline$\dot{m}_{\mathrm{ref}, \text { out }, i}$ & $\begin{array}{l}\text { Mass flow rate of the refrigerant leaving each of the } \\
\text { display case's evaporators }\end{array}$ \\
\hline$m_{\text {suc }}$ & Total mass of refrigerant in the suction line \\
\hline$\dot{m}_{\text {suc,in }}$ & Mass flow rate into the suction line \\
\hline$N_{\text {comp }}$ & Number of running compressors \\
\hline$N_{D C}$ & Number of display cases in the system \\
\hline OD & Opening degree of the expansion valve \\
\hline Prec & Pressure in the receiver \\
\hline$P_{\text {suc }}$ & Pressure in the suction line \\
\hline$\dot{Q}_{e}$ & $\begin{array}{l}\text { Heat transfer from the evaporator wall to the } \\
\text { refrigerant in the evaporator, also termed to the } \\
\text { cooling capacity }\end{array}$ \\
\hline Q Qroducts $_{\text {S }}$ & $\begin{array}{l}\text { Heat transfer from the products to the air inside the } \\
\text { display case }\end{array}$ \\
\hline$\dot{Q}_{\text {indoor }}$ & $\begin{array}{l}\text { Heat load from the indoor supermarket temperature } \\
\text { and local environment }\end{array}$ \\
\hline$T_{\text {air }- \text { off }}$ & Temperature at the back of the display case \\
\hline$T_{\text {air }- \text { on }}$ & Temperature at the front of the display case \\
\hline$T_{e}$ & $\begin{array}{l}\text { Evaporation temperature of the refrigerant in the } \\
\text { evaporator }\end{array}$ \\
\hline$T_{\text {products }}$ & Temperature of the products in the display case \\
\hline $\begin{array}{l}T_{\text {products, }} \\
\text { initial }\end{array}$ & Initial temperature of the products in the display case \\
\hline$T_{\text {indoor }}$ & Indoor temperature of the supermarket \\
\hline$T_{\text {shelf }}$ & $\begin{array}{l}\text { Weighted combination of temperature probes in the } \\
\text { display case }\end{array}$ \\
\hline$U A_{i}$ & $\begin{array}{l}\text { Overall heat transfer coefficient, where } i \text { denotes the } \\
\text { media which heat is transferred across }\end{array}$ \\
\hline$\dot{V}_{\text {comp }}$ & Volumetric flow rate leaving the suction line \\
\hline$V_{\text {Evap, } \max }$ & Maximum volume of the evaporator \\
\hline
\end{tabular}

(Continued)

\begin{tabular}{lll}
\hline Symbol & Parameter description & Unit \\
\hline$\dot{V}_{d}$ & $\begin{array}{l}\text { Maximum displacement volume rate of each } \\
\text { compressor }\end{array}$ & $\mathrm{m}^{3} / \mathrm{s}$ \\
$V_{\text {suc }}$ & Volume of the suction line & $\mathrm{m}^{3}$ \\
$\dot{W}_{\text {comp }}$ & Power consumption of the compressor pack & $\mathrm{kW}$ \\
$a$ & Empirical constant for display case probes & - \\
$\beta$ & Empirical constant for display case probes & - \\
$\eta_{\text {vol }}$ & Clearance volumetric efficiency & $\%$ \\
$\rho_{\text {comp }}$ & Density of the refrigerant leaving the compressors & $\mathrm{kg} /$ \\
& & $\mathrm{m}^{3}$ \\
$\rho_{\text {liq, rec }}$ & Density of the liquid refrigerant passing through the & $\mathrm{kg} /$ \\
& expansion valve & $\mathrm{m}^{3}$ \\
$\rho_{\text {liq, suc }}$ & Density of the liquid refrigerant in the evaporator & $\mathrm{kg} /$ \\
& & $\mathrm{m}^{3}$ \\
$\rho_{\text {suc }}$ & Density of the suction line & $\mathrm{kg} /$ \\
& & $\mathrm{m}^{3}$ \\
\hline
\end{tabular}

$\mathrm{kg}$

$\mathrm{kg} / \mathrm{s}$

$\mathrm{kg}$

$\mathrm{kg} / \mathrm{s}$

$\mathrm{kg} / \mathrm{s}$

$\mathrm{kg}$

$\mathrm{kg} / \mathrm{s}$

$-$

$-$

$-$

\section{Introduction}

The use of refrigeration systems in industries such as food production, pharmaceuticals and breweries is allowed for developments to be made in each respective field and are largely relied on daily operations. The UK food and drink industry accounts for $£ 188$ billion of consumer expenditure and counts on refrigeration systems for rapid cooling of meat, fruits and vegetables to extend their product life and to prevent the growth of harmful bacteria [1, 2]. Refrigeration systems in the brewery industry are the largest single process consumers of electricity demanding $32 \%$ of the electricity provided to this sector [3-5]. Pharmaceutical products require controlled cooling storages in order to maintain efficacy and their safety $[6,7]$.

The refrigeration systems for local food transportation are designed to operate dependably in severe environments in comparison with the domestic or commercial systems [8], resulting in low operating efficiencies than that of stationary refrigeration systems ${ }^{\circ} \mathrm{C}$ [9]. Moreover, the increasing demand for transported ${ }^{\circ} \mathrm{C}$ refrigerated products has emphasised potential ${ }^{\circ} \mathrm{C}$ developments in order to reduce energy consumption and improve system performance. Refrigerated food transport in the UK is responsible for a $1.8 \%$ of emissions [10], whilst refrigeration systems for the international shipping transportation are responsible for emitting about $15 \mathrm{Mt}$ $\mathrm{CO}_{2}$ [11]. Most transporter ships do not have the refrigerating capacity for fast cooling, so all products must be already pre-cooled prior to loading [12].

In commercial sectors, the improper cooling of food in kW/ $\mathrm{K}$ restaurants and food outlets is a major cause of foodborne illness [13]. The food code presented by the US Food and Drug Administration states that potentially hazardous food must be rapidly cooled from 57.5 to 
$21.1^{\circ} \mathrm{C}$ in $2 \mathrm{~h}$ or less and from 21.1 to $5^{\circ} \mathrm{C}$ in an additional $4 \mathrm{~h}$ or less [14]. The importance of rapid cooling in preventing pathogens growing on food shows how heavily dependent restaurants are upon highly performing refrigeration systems.

Commercial food outlets in the UK are responsible for around $12 \mathrm{TWh}$ of annual electrical consumption, about $3 \%$ of the UK total energy consumption and $1 \%$ of total green house gas (GHG) emissions [2]. Furthermore, the leakage of refrigerant from supermarkets is accountable for $2 \mathrm{Mt} \mathrm{CO}_{2}$ emissions per year caused by the leakage of hydrofluorocarbons (HFC) [15]. Improving the performance of the refrigeration system has a huge potential in reducing electrical usage and costs. Furthermore, reducing electrical usage will consequently aid in the decrease of GHG emissions, particularly carbon dioxide, and lower the industries' carbon footprint. Additionally, due to the food outlets in the UK operating on a small profit margin typically around 1$2 \%$, the importance of energy savings is vital. A large potential for energy savings has been identified $[2,16]$; as the refrigeration system can use up to $60 \%$ of the total store energy, they have been identified as an area of particular interest [17]. Therefore, further research and investigations are necessary to determine a reliable engineering approach of energy saving for commercial refrigeration systems.

Refrigeration systems are a common feature in supermarkets for the preservation of chilled and frozen products. The layout of the refrigeration system of the supermarket is shown in Fig. 1. In supermarkets, the refrigeration systems are split into low-temperature (LT) systems for frozen products and high-temperature (HT) systems for non-frozen products [18]. All compressors operate at the same saturated suction temperature, often configured in packs where the compressors can be selected and cycled as needed to meet the refrigeration load [19]. The compressors compress the low-pressure refrigerant which is returning from the display case via the suction manifold to the condenser unit [18]. There are two levels of temperatures within food outlets which both have different purposes, $0-8{ }^{\circ} \mathrm{C}$ for the preservation of fresh products and beverages and around $-18^{\circ} \mathrm{C}$ for frozen products [16].

Tassou et al. [20] reported that food outlets in the UK are characterised by their average sales area and their annual average electrical energy consumption. The electrical energy consumption for refrigeration systems is expected to be higher within smaller supermarkets and convenience stores as they have a higher focus on chilled and frozen foods with less additional services instore to consume electricity. In the food industry, refrigeration systems account for between 30 and $60 \%$ of the electricity used with hypermarket refrigeration systems accounting for $29 \%$ of their annual consumption [21].

Due to the growing demand on refrigeration systems, there has been remarkable interest in developing more efficient and better-performing systems [22]. Larsen [18] developed a nonlinear dynamic mathematical model of the supermarket refrigeration system. The model is a combination of individual models for the display cases, suction manifold, compressor pack and condenser unit with the main emphasis on modelling the suction manifold and display cases. Peterson et al. [23] adapted the

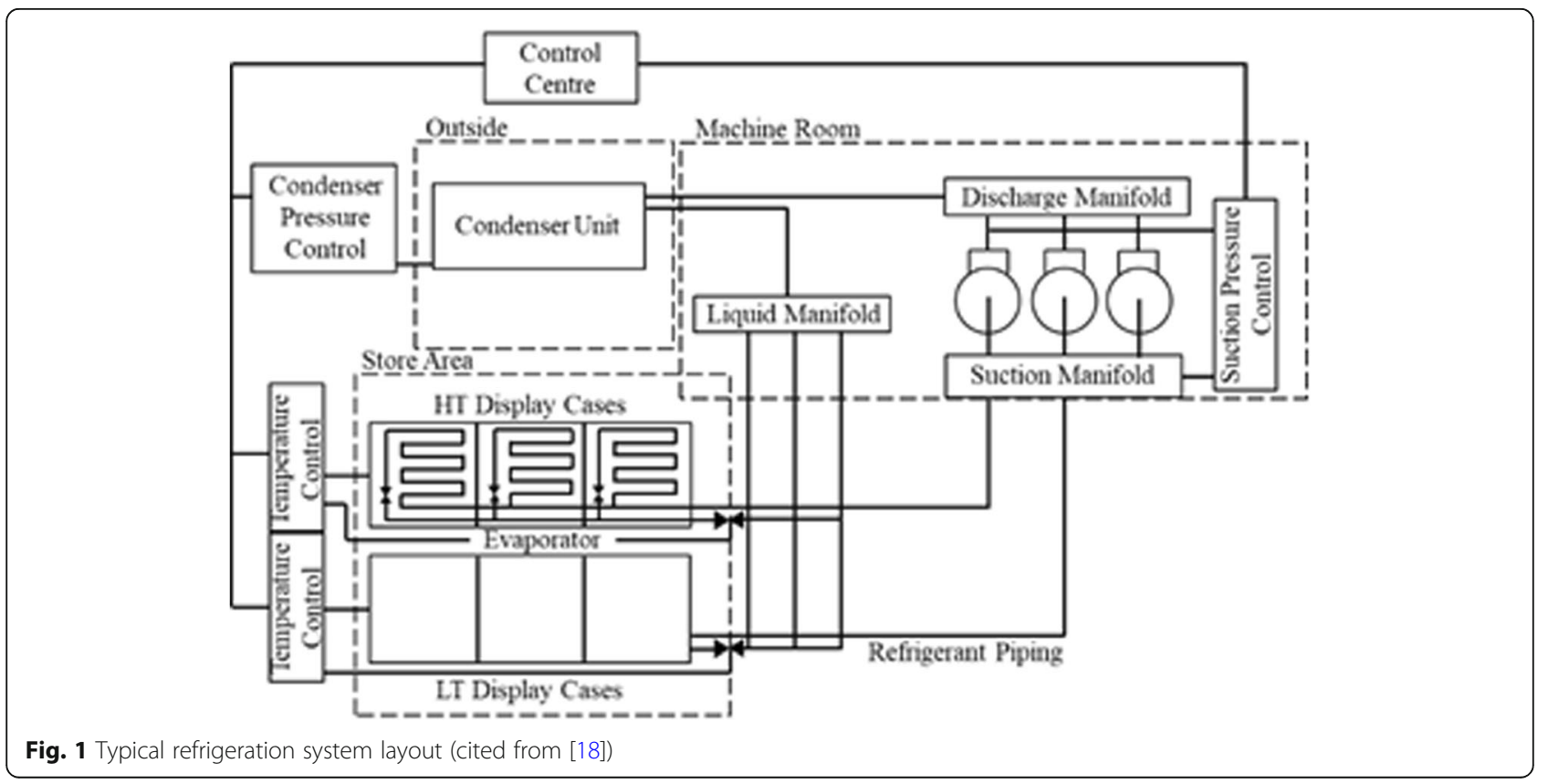


model of Larsen [18] with more focus on optimisation of supermarket refrigeration systems. A classic control setup introduced disturbances, and the dynamic coupling of the cases caused the synchronisation of compressors, which leads to lowering the system efficiency.

Shafiei et al. [22] developed a supermarket refrigeration system for smart grid applications with the focus primarily on estimating the compressor power consumption and cold reservoir temperatures.

A mathematical model to simulate the performance of a supermarket refrigeration system has been proposed by Ge and Tassou [24]. The model allows for the comparison between different systems in terms of their energy and total equivalent warming impact, where the total equivalent warming impact was defined as the sum of the direct and indirect emissions of greenhouse gases.

Sarabia et al. [25] proposed a nonlinear continuoustime model to investigate a nonlinear model predictive control (MPC) and to calculate the output predictions. The model was inspired by a publication from Larsen et al. [26].

Glavan et al. [27] developed a dynamic model refrigeration system that can determine the impact of component efficiency and losses due to interaction with the system. A state-space model has been presented which represents a linear heat transfer dynamic of the display case with the real temperature dynamics used. The work done in [27] was inspired by the work of Kasper et al. [28] where a model has been presented to aid in the investigation of a precooling algorithm.

Posnikov et al. [29] presented a large scale control model of a retail refrigeration system for a static firm frequency response. Two methods of control were tested, modulation and hysteresis; however, hysteresis leads to undesired load oscillations following a shedding event. The study also shows that active power fluctuates in response to a frequency balancing event, allowing the system to be linked to a power grid model to simulate power loss. Saleh et al. [30] investigated the impact of responding to demand side response events on the performance of the commercial refrigeration system, using a large network of compressor packs.

The impact of various operational parameters on the performance of the commercial refrigeration system has been examined, and the model has been validated previously by the group or research at the University of Lincoln and published in [31]. The aim of this paper is to extend the previous work to examine and investigate the impact of indoor temperature variations on the performance of the refrigeration system. However, only the governing equations of the model will be presented in this paper to ensure validity and coherence of the research, whilst the validation of the model will be excluded in order to avoid redundancy. Different failures of air conditioning (AC) systems and their impacts on refrigeration performance and energy consumption will be investigated and examined.

\section{Commercial refrigeration system model}

A model is composed of four main subsystems, the expansion valve and the evaporator of the display cases, the suction lines, the compressor pack and the condenser, as shown in Fig. 2. These individual models are then combined to model a full commercial refrigeration system, allowing for different system configurations to be tested effectively. Particular emphasis during modelling has been given on the display cases and the compressor pack in order to accurately estimate food temperature and its safety, as well as power consumption, as presented in [31]. Additionally, the developed model has been validated using a real data from a functioning refrigeration system at the Riseholme Refrigeration Research Centre to ensure the accuracy of the simulation. Also, the developed model will be capable of estimating the refrigerant properties, power consumption and system temperatures, as well as investigations into store/system parameters and their effect on power consumption; further details of this model can be found in [31].

The model proposed in this research will mimic a typical 2000 sq. $\mathrm{ft}$ express supermarket located at the Riseholme Refrigeration Research Centre at the University of Lincoln, as it has been published in [31]. Figure 3 shows the layout of the store which comprises 13 high-temperature (HT) display cases, of two different models (Atlas FHGD and Monza FHGD), and 2 lowtemperature (LT) freezers, model Hockenheim. A hysteresis controller is used to control the opening valve and hence the temperature of each display case. The upper and lower setpoints for the HT display cases are set at $3{ }^{\circ} \mathrm{C}$ and $0{ }^{\circ} \mathrm{C}$, respectively, whilst the LT freezer setpoints are $-21^{\circ} \mathrm{C}$ and $-23^{\circ} \mathrm{C}$. The temperature setpoints of the LT display cases are set using readings from the $T_{\text {air - off probe. Whilst the HT display cases are }}$ set using a combination of the $T_{\text {air-on }}$ and $T_{\text {air-off }}$ probes with a weighting applied of $40 \%$ from $T_{\text {air-on }}$ and $60 \%$ from $T_{\text {air-off. The case controllers used are }}$ Danfoss 514B and Danfoss 550 whilst the HT expansion valves are AKV10 and the LT expansion valves are TEX $[29,30]$. Both the HT and LT systems have separate suction lines which are maintained at 3.4 bar and 0.7 bar, respectively, and discharge the refrigerant to a common liquid line which is at a constant pressure of $11 \mathrm{bar}$. The compressor pack comprised a total of 6 Copeland scroll compressors as shown in Fig. 4 (4 HT compressors, model ZB45KCE; 2 LT compressors, models ZF09K4E and ZF15K4E); all compressors operate with fixed volume displacements; hence, they operate at $100 \%$ 


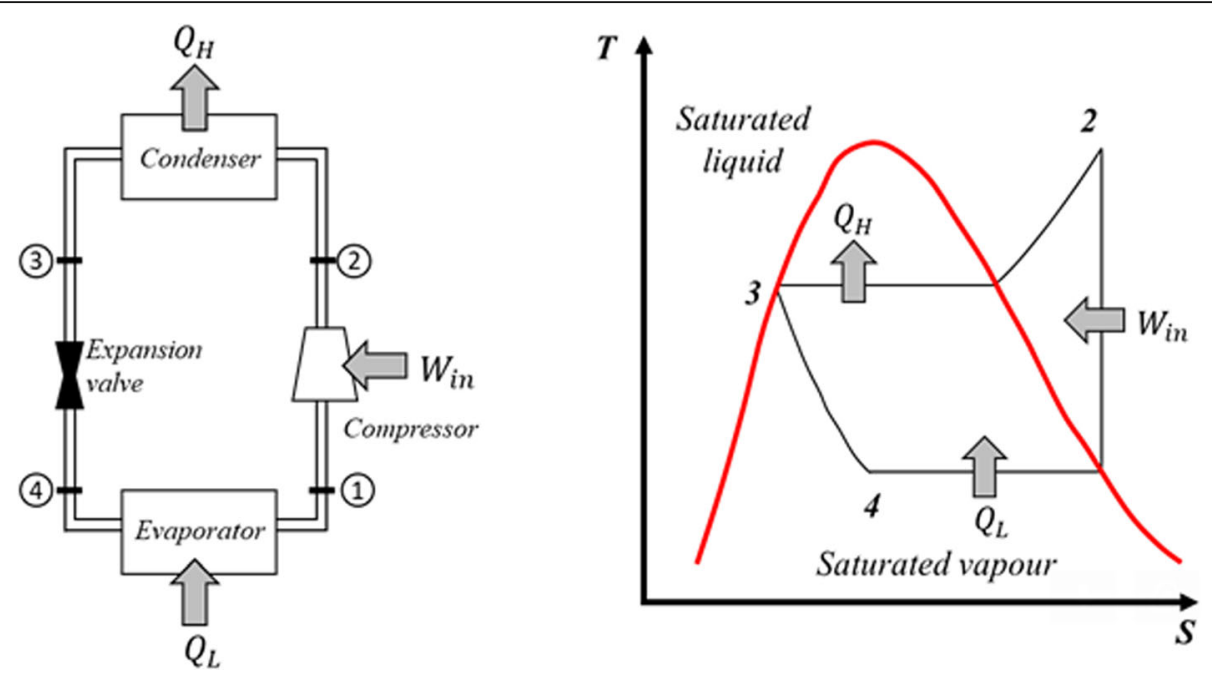

Fig. 2 The main subsystems and refrigeration cycle for the refrigeration system (cited from [31])

capacity. The average power drawn by each individual compressor is around $4.25 \mathrm{~kW}[29,30]$.

The compressor pack runs in a first-in first-out (FIFO) sequence in order to maintain the desired suction line pressure [32]. This sequence operates so that more compressors turn on once the suction pressure reaches an upper bound and all shut off once a lower bound is reached. Around the reference, pressure is a neutral margin in which none of the compressors is turned on nor off as illustrated in Fig. 5 [29, 32]. The refrigerant used in this system is R407F; a high critical temperature value of $82.7^{\circ} \mathrm{C}$ of $\mathrm{R} 407 \mathrm{~F}$ ensures that the refrigerant will be fully liquified in the condenser, ensuring that the refrigerant into the evaporator, $\dot{m}_{\text {ref,in }}$ is in a $100 \%$ liquid state. This allows for the maximum heat transfer to occur, helping to lower power consumption and decrease energy usage by up to $15 \%$ when compared to R404A [33-35]. A summary of the commercial refrigeration system parameters used in the presented model is displayed in Table 1 [31].

For the purpose of modelling the system, two models developed by Larsen [18] and Petersen et al. [23] are adopted, with additional contributions provided from Shafei et al. [22], Sarabia et al. [32] and Vinther [36]. Existing models by Postnikov et al. in $[29,39]$ based on the Riseholme Refrigeration Research Centre are used to provide specific theory and understanding of the facility itself.

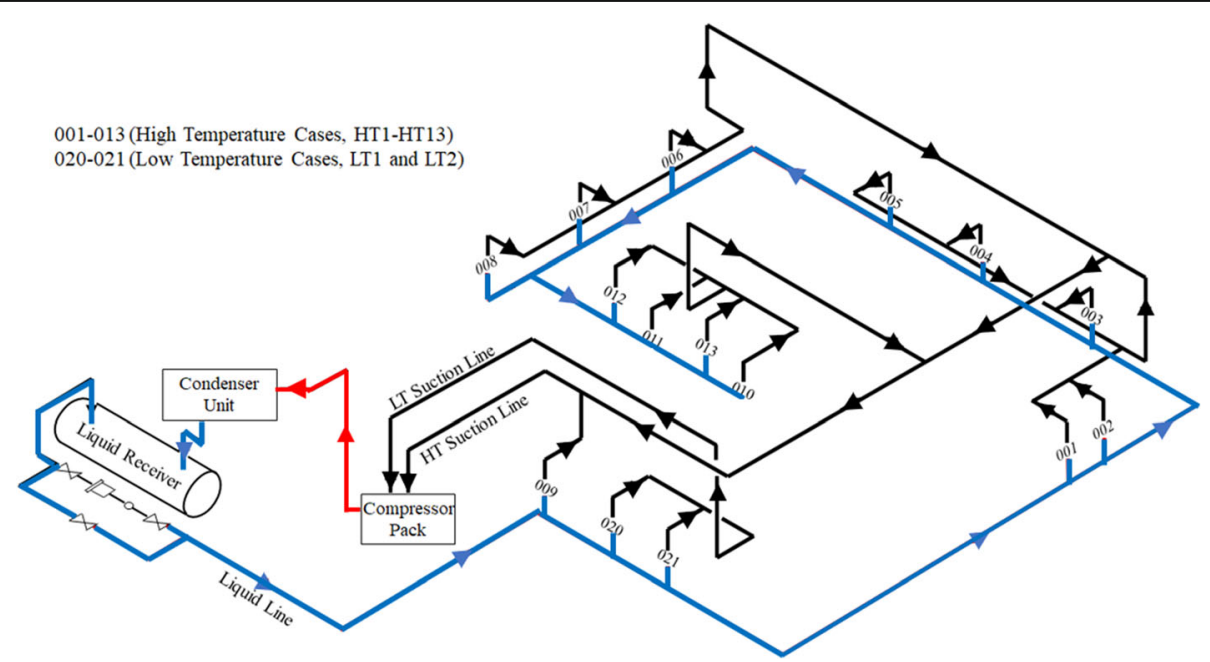

Fig. 3 Schematic layout of the Riseholme Refrigeration Research Centre (cited from [30]) 


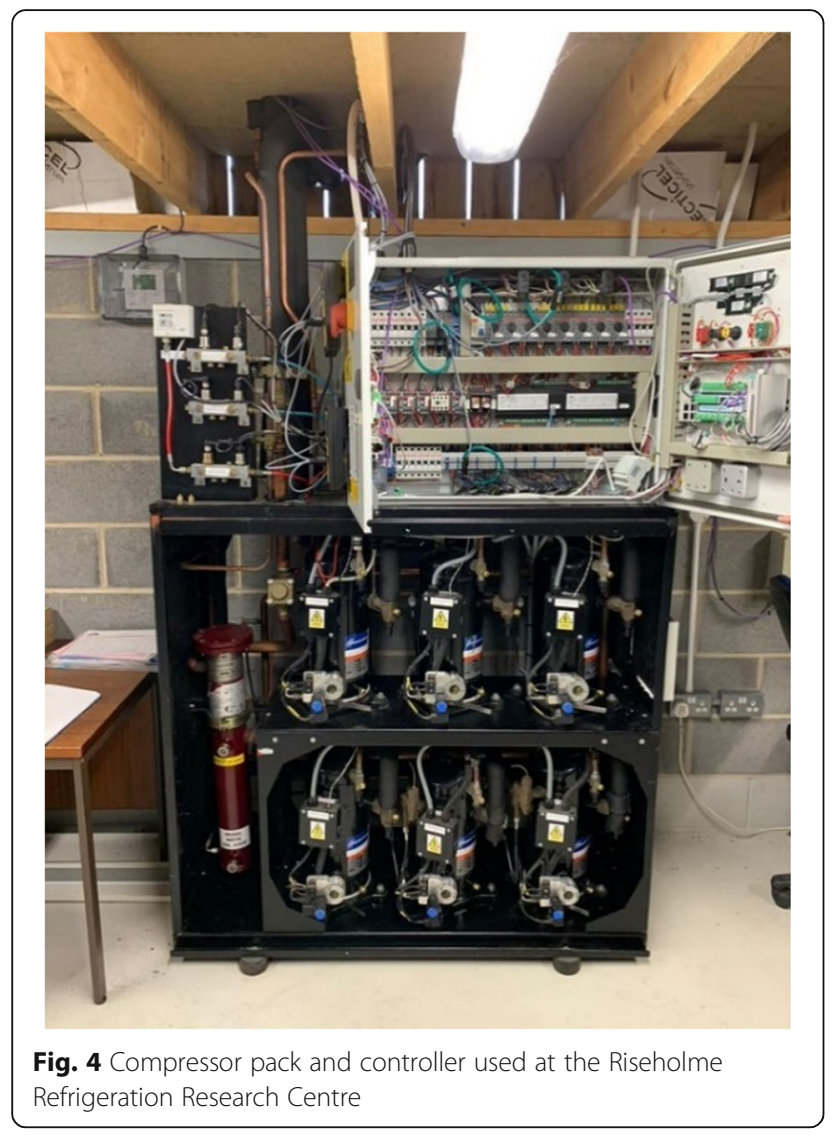

The developed model is composed of three main subsystems: the display cases, suction line and compressor pack. In order to simplify the model, it is assumed that the condensers have a full condensation with a $100 \%$ liquid return, and the condenser dynamics and the pressure within the return line are stable; therefore, any changes that occur are negligible in the overall system. A static relation can therefore be used to calculate the properties in the condenser with the liquid line, receiver and condenser assumed to be constant at $11 \mathrm{bar}$; it has also been assumed that subcooling is constant $[29,40]$. The refrigerant properties used are calculated using the REFPROP database. The developed system is modelled using a refrigerant R407F [41].

\subsection{Display cases: expansion valve and evaporator}

In a commercial refrigeration system, the display cases provide a low-temperature environment for the products to be safely stored. The display case consists of an evaporator, an expansion valve and a storage compartment. Inside the display case, the heat from the products is transferred to the evaporator via a circulating air curtain $[18,23]$. Incoming refrigerant to the evaporator is controlled by the expansion valve which regulates the mass flow rate of the refrigerant by adjusting the opening degree of the valve. The dynamics of the display cases are derived from creating an energy balance for the products, evaporator and air inside the display case along with a mass balance for the refrigerant in the evaporator. For this model, all frictional and minor losses are assumed to be negligible. Figure 6 shows a typical layout of the high-temperature (HT) commercial refrigeration display case which is used to derive the main equations in this research [18, 25, 39].

Assuming a lumped temperature model, the following state equations are then given by $[18,23]$ :

$$
\begin{aligned}
& \frac{d T_{\text {products }}}{d t}=\frac{-\dot{Q}_{\text {products }}}{m_{\text {products }} C_{p, \text { products }}} \\
& \frac{d T_{\text {air }}}{d t}=\frac{\dot{Q}_{\text {products }}+\dot{Q}_{\text {indoor }}-\dot{Q}_{e}}{m_{\text {air }} C_{p, \text { air }}}
\end{aligned}
$$

where $m, t$ and $C_{p}$ are the mass, time and the heat capacity, respectively, with each subscript denoting the media which the parameter refers to; $\dot{Q}_{\text {products }}$ is the heat transfer from the products to the air inside the display

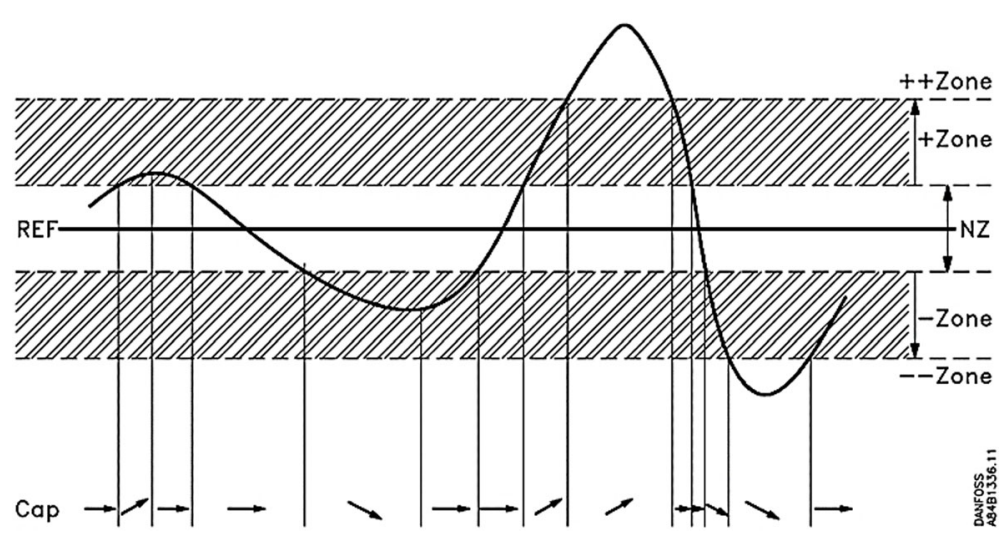

Fig. 5 First-in first-out (FIFO) compressor operation cycle (cited form [32]) 
Table 1 Summary of the system parameters used in the presented model [29, 30, 36-38]

\begin{tabular}{|c|c|c|c|}
\hline Component & Parameters & Parameter description & Value \\
\hline \multirow[t]{8}{*}{ Display cases and expansion valve } & - & Number of HT cases & 13 \\
\hline & - & Number of LT cases & 2 \\
\hline & $V_{\text {Evap, max }}$ & Maximum volume of the evaporator & $0.019 \mathrm{~m}^{3}$ \\
\hline & $C_{V}$ & Collection of valve constants & $4.72 \mathrm{e}-6 \mathrm{~s} / \mathrm{m}^{2}$ \\
\hline & \multirow[t]{2}{*}{ HT temperature setpoints } & HT upper setpoint & $3^{\circ} \mathrm{C}$ \\
\hline & & HT lower setpoint & $0^{\circ} \mathrm{C}$ \\
\hline & \multirow[t]{2}{*}{ LT temperature setpoints } & LT upper setpoint & $-21^{\circ} \mathrm{C}$ \\
\hline & & LT lower setpoint & $-23^{\circ} \mathrm{C}$ \\
\hline \multirow[t]{7}{*}{ Compressor pack } & \multirow[t]{3}{*}{$\dot{V}_{d}$} & HT compressor displacement volume & $0.0047 \mathrm{~m}^{3} / \mathrm{s}$ \\
\hline & & LT compressor 1 displacement volume & $0.0022 \mathrm{~m}^{3} / \mathrm{s}$ \\
\hline & & LT compressor 2 displacement volume & $0.0040 \mathrm{~m}^{3} / \mathrm{s}$ \\
\hline & - & Number of HT compressors & 4 \\
\hline & - & Number of LT compressors & 2 \\
\hline & - & FIFO neutral offset & $10.1 \mathrm{kPa}$ \\
\hline & - & FIFO additional offset & $15.2 \mathrm{kPa}$ \\
\hline Discharge line & $P_{\text {rec }}$ & Pressure in the receiver & $1114 \mathrm{kPa}$ \\
\hline
\end{tabular}

case; $\dot{Q}_{\text {indoor }}$ is the heat load from the indoor supermarket store temperature to the air inside the display case; and $\dot{Q}_{e}$ is the heat transfer from the air inside the display case to the refrigerant in the evaporator and is also termed the cooling capacity. The two states are, therefore, $T_{\text {products }}$ and $T_{\text {air }}$ which are the temperature of the products and air inside the display case, respectively. The energy flows are then defined by [23]:

$$
\begin{aligned}
& \dot{Q}_{\text {products }}=U A_{\text {products }}\left(T_{\text {products }}-T_{\text {air }}\right) \\
& \dot{Q}_{\text {indoor }}=U A_{\text {indoor }}\left(T_{\text {indoor }}-T_{\text {air }}\right)
\end{aligned}
$$

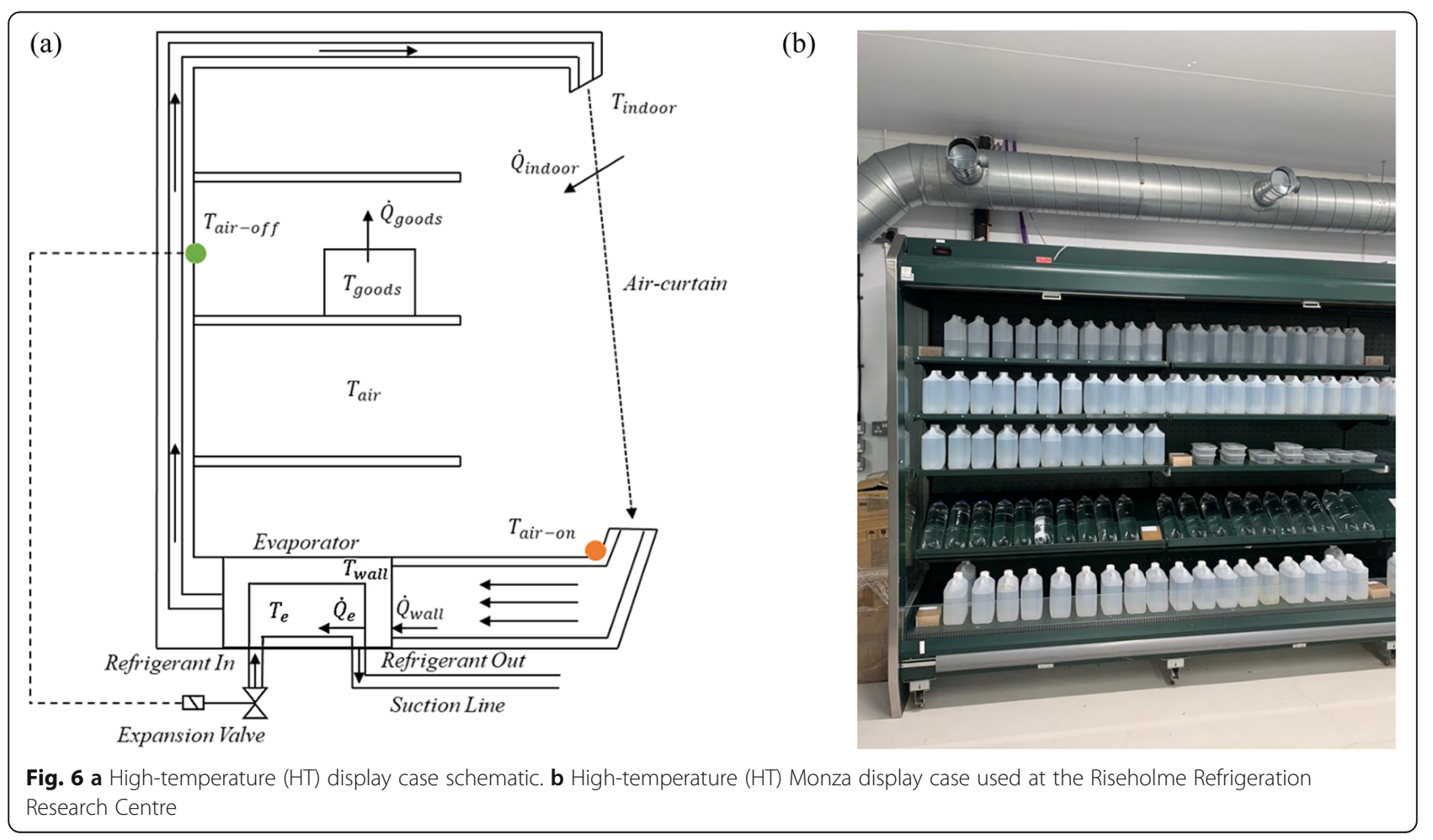




$$
\dot{Q}_{e}=U A_{e}\left(T_{\mathrm{air}}-T_{e}\right)
$$

where $U A$ is the overall heat transfer coefficient with the subscript denoting the media which the heat is transferred across, $T_{\text {indoor }}$ is the indoor store temperature of the supermarket and $T_{e}$ is the evaporation temperature of the refrigerant which is a function of pressure and is dependent on the refrigerant used in the system $[18,23,25]$. This is therefore calculated from the suction line dynamics using the refrigerant properties database REFPROP [42]. Combining Eqs. (1) and (3) and solving for the product temperature lead to:

$$
T_{\text {products }}=T_{\text {air }}\left(T_{\text {products,initial }}-T_{\text {air }}\right) e^{\left(\frac{U A_{\text {products }}{ }^{-1}}{m_{\text {products }} C_{p \text { products }}}\right)}
$$

where $T_{\text {products, initial }}$ is the initial temperature of the products at the start of the system simulation. Combining Eqs. (2) and (6) and assuming the specific heat capacity of the air is close to zero, Eq. (2) can be solved to find the temperature of the air inside the display case, $T_{\text {air }}$ [23]:

$$
T_{\text {air }}=\frac{U A_{\text {products }} T_{\text {products }}+U A_{\text {indoor }} T_{\text {indoor }}+U A_{e} T_{e}}{U A_{\text {products }}+U A_{\text {indoor }}+U A_{e}}
$$

In order to monitor the range of temperatures of the air inside the display case, two temperature probes are used. These are positioned at the front and rear of the display case with the probe at the front being 'on' the air curtain and the rear probe being 'off' the air curtain, giving them the names $T_{\text {air-on }}$ and $T_{\text {air-off, }}$ respectively. The readings from the $T_{\text {air-off }}$ probe are a calculated ratio between $T_{\text {air }}$ and $T_{e}$, similarly $T_{\text {air - on }}$ is calculated from a ratio between $T_{\text {air }}$ and $T_{\text {indoor }}$ [29]:

$$
\begin{aligned}
& T_{\text {air-off }}=\propto T_{\text {air }}+(1-\alpha) T_{e} \\
& T_{\text {air-on }}=\beta T_{\text {air }}+(1-\beta) T_{\text {indoor }}
\end{aligned}
$$

where $\alpha$ and $\beta$ are empirical coefficients that are dependent on the type of display case, location in the supermarket and outdoor temperature [29]. The heat transfer coefficient between the evaporator and the refrigerant, $U A_{e}$, is assumed to be a linear function of the mass of liquefied refrigerant in the evaporator, $m_{\mathrm{ref}}$ $[18,22]$ :

$$
U A_{e\left(m_{\mathrm{ref}}\right)}=k_{m} U A_{e}
$$

where $k_{m}$ is defined as the ratio of the mass of refrigerant in the evaporator, to the maximum capacity of the evaporator, $m_{\text {ref, } \max }[18,22]$ :

$$
k_{m}=\frac{m_{\mathrm{ref}}}{m_{\mathrm{ref}, \max }}
$$

Due to the variations of pressure and temperature of the liquified refrigerant inside the evaporator, the density therefore varies as a result. Therefore, $m_{\text {ref, }}$ $\max$ is constrained by the maximum volume of the evaporator $V_{\text {Evap, max }}$ and the density of the liquified refrigerant $\rho_{\text {liq, suc }}$ which is calculated using the REFP ROP database [42]:

$$
m_{\text {ref, max }}=V_{\text {Evap, } \max } \times \rho_{\text {liq,suc }}
$$

The rate of change of refrigerant in the evaporator $\frac{d m_{\text {ref }}}{d t}$ is defined by the mass balance in and out of the evaporator [22, 23]:

$$
\frac{d m_{\mathrm{ref}}}{d t}=\dot{m}_{\mathrm{ref}, \text { in }}-\dot{m}_{\mathrm{ref}, \mathrm{out}}
$$

where $\dot{m}_{\text {ref,in }}$ and $\dot{m}_{\text {ref,out }}$ are the mass flow rate of the refrigerant in and out of the evaporator, respectively. The mass flow rate entering the evaporator is controlled by the expansion valve via regulating the opening degree of the valve. This is governed by Bernoulli's equation, assuming laminar flow and no change in elevation [40]:

$$
\dot{m}_{\mathrm{ref}, \text { in }}=O D \cdot C v \cdot \sqrt{\rho_{\text {liq }, \mathrm{rec}}} \cdot \sqrt{P_{\text {rec }}-P_{\text {suc }}}
$$

where $O D$ is the opening degree of the valve with 0 being fully closed and 1 being fully open; $C v$ is a collection of constants, such as the cross-sectional area of the valve inlet and outlet, and can also be termed the orifice coefficient or valve characterising constant [23, 40]; and $P_{\text {rec }}$ and $P_{\text {suc }}$ are the pressure in the receiver and the suction line, respectively. The mass flow rate of refrigerant leaving the evaporator is assumed to be $100 \%$ dry vapour with a constant superheat temperature and is given by [40]:

$$
\dot{m}_{\text {ref,out }}=\frac{\dot{Q}_{e}}{h_{l g, \text { out }}-h_{l g, \text { in }}}
$$

where $h_{l g}$, out and $h_{l g}$, in are the enthalpies of the refrigerant at the outlet and inlet of the evaporator, respectively [40]. These enthalpies are calculated from the suction line pressure using the REFPROP database [39, 42]. By combining Eqs. (10), (11), (12), (13), (14) and (15), the accumulation of refrigerant in the evaporator can be calculated, and therefore, the overall heat transfer coefficient between the refrigerant and evaporator can be determined.

Due to practical difficulties involved in directly measuring the product temperature, a filtered $30 \mathrm{~min}$ of readings based on shelf temperature $T_{\text {shelf }}$ is used to 
provide a calculated product temperature $(\mathrm{CPT})$ for each case. This can be described as $[29,30]$ :

$$
\mathrm{CPT}_{k}=\frac{1}{30}\left(\sum_{i=1}^{29} \mathrm{CPT}_{k-i}+T_{\text {shelf }}^{k}\right)
$$

where the subscript $k$ denotes the minute at which the measurements and calculations are done. $T_{\text {shelf }}$ can be calculated from the readings taken by the air-on and airoff probes located in each of the cases as follows [29, 30]:

$$
T_{\text {shelf }}=0.6 T_{\text {air-off }}+0.4 T_{\text {air-on }}
$$

\subsection{Suction line}

The suction line is modelled by a dynamic equation with one state $P_{\text {suc }}$ of the suction pressure. Establishing the mass balance across the suction line [23]:

$$
\frac{d m_{\text {suc }}}{d t}=\dot{m}_{\text {suc,in }}-\dot{V}_{\text {comp }} \rho_{\text {suc }}
$$

where $m_{\text {suc }}$ is the total mass of refrigerant in the suction line; the mass flow rate thar enters the suction line is the sum of all mass flow rates leaving each of the display case evaporators [23]:

$$
\dot{m}_{\text {suc }, \text { in }}=\sum_{i}^{N_{D C}}\left(\dot{m}_{\text {ref }, \text { out }, \mathrm{i}}\right)
$$

where $N_{D C}$ is the number of display cases, $\dot{m}_{\text {suc,in }}$ is the mass flow rate that enters the suction line and $\dot{m}_{\text {ref,out }, i}$ is the mass flow rate of the refrigerant leaving the evaporator. Rewriting the mass derivative in terms of volume, density and pressure yields [23]:

$$
\frac{d m_{\mathrm{suc}}}{d t}=V_{\mathrm{suc}} \frac{d \rho_{\mathrm{suc}}}{d t}=V_{\mathrm{suc}} \frac{d \rho_{\mathrm{suc}}}{d P_{\mathrm{suc}}} \frac{d P_{\mathrm{suc}}}{d t}
$$

where $V_{\text {suc }}$ and $\rho_{\text {suc }}$ are the volume and density of the refrigerant in the suction line, respectively. By combining Eqs. (18) and (20) and rearranging for $\frac{d P_{\text {suc }} \text {, }}{d t}$, the final dynamic equation for the suction line is [23]:

$$
\frac{d P_{\text {suc }}}{d t}=\frac{\dot{m}_{\text {suc }, \text { in }}-\dot{V}_{\text {comp }} \rho_{\text {suc }}}{}
$$

where $\dot{V}_{\text {comp }}$ is the volumetric flow rate leaving the suction line and is determined from the compressor duty cycle [23].

\subsection{Compressor pack}

The compressor pack receives the refrigerant from the display cases via the suction line. The compressors in this system operate as discrete fixed volumes; thus, each compressor is either running at maximum capacity or is totally off. The operation of the compressors is functioned to the suction line pressure; the flow rate of the compressors can therefore be modelled as [23]:

$$
\dot{V}_{\text {comp }}=N_{\text {comp }} \dot{V}_{d} \eta_{\text {vol }}
$$

where $N_{\text {comp }}$ is the number of running compressors, $\dot{V}_{d}$ is the maximum displacement volume flow rate of each compressor and $\eta_{\mathrm{vol}}$ is the clearance volumetric efficiency [22]. The average power drawn by one compressor running at maximum capacity is $4.25 \mathrm{~kW}$; therefore, the total compressor power consumption can be found in Eq. (23) [29]:

$$
\dot{W}_{\text {comp }}=4.25 N_{\text {comp }}
$$

where $W_{\text {comp }}$ is the power consumption $(\mathrm{kW})$ of the entire compressor pack.

\section{Validation of the developed model}

In order to tune and validate the developed refrigeration system model, MatLab and Simulink are used to simulate the operation of the developed model. The results of the model simulation will be analysed and compared with a real operational data collected from the refrigeration system at the Riseholme Refrigeration Research Centre. The real operational data has been collected on 18 March 2017 during a 3-h period between 08:30 and 11:30, with a data granularity of 1 sample per minute and an average store temperature of $16^{\circ} \mathrm{C}$. The parameters that were manually tuned in MatLab to validate and create a resemblance between the real data and the simulation results are as shown in Table 2.

The air-on, air-off and product temperatures for the simulation results of the developed model and for the collected real data are shown in Figs. 7 and 8, respectively, whilst the operation of the expansion valve for the developed model and for the real data are shown in Figs. 9 and 10, respectively.

From Figs. 7 and 8, the general trends for both the simulation and real data are resembled throughout the 3- $\mathrm{h}$ operation. The product temperature determined by the air-on and air-off temperatures is $2.1^{\circ} \mathrm{C}$ for both the simulation and real data. Additionally, both the air-on and air-off temperatures have similar maximum values. For air-on, $3.87^{\circ} \mathrm{C}$ for the simulated results and $4{ }^{\circ} \mathrm{C}$ for the real data, whilst for air-off, $3.02{ }^{\circ} \mathrm{C}$ for the simulated results and $3{ }^{\circ} \mathrm{C}$ for the real data. The simulation results consistently have lower minimum temperature values for both air-on and air-off when compared to the real data. The minimum air-on temperatures were $0.25^{\circ} \mathrm{C}$ for the simulated results and $2.3^{\circ} \mathrm{C}$ for the real data. Whilst. the minimum air-off temperatures were $0.78^{\circ} \mathrm{C}$ for the simulated results and $-0.4^{\circ} \mathrm{C}$ for the real data. This difference is caused by modelling all 13 
Table 2 Tuned parameters used for the validation of the developed model

\begin{tabular}{llll}
\hline Components & Parameters & Parameter description & Values \\
\hline Display cases & $\propto$ & Empirical coefficient of $T_{\text {air-off }}$ & 0.952 \\
& $\beta$ & Empirical coefficient of $T_{\text {air-on }}$ & 0.970 \\
& $U A_{\text {products }}$ & Heat transfer coefficient between products and air inside DC & $0.001 \mathrm{~kW} / \mathrm{K}$ \\
& $U A_{\text {indoor }}$ & Heat transfer coefficient between indoor and air inside HT DC & $0.032 \mathrm{~kW} / \mathrm{K}$ \\
& $U A_{e, \text { full }}$ & Maximum heat transfer coefficient between DC air and liquified refrigerant in evaporator & $0.450 \mathrm{~kW} / \mathrm{K}$ \\
& $m_{\text {products }}$ & Mass of products & $1200 \mathrm{~kg}$ \\
Suction line & $C_{p, \text { products }}$ & Specific latent heat of Products & $4.18 \mathrm{~kJ} / \mathrm{kg}$ \\
\hline
\end{tabular}

display cases as the same, and all acting at the same time, which causes an exaggerated demand on the system and leads to lower temperatures in the display cases. Furthermore, the real data for the Riseholme Refrigeration Centre features two different HT display types with a few different sizes, all acting on their individual loads. However, the model presented in this paper assumes all 13 display cases are identical in types and loads. The sharp drop noted in Fig. 7 near the bottom of the curve, which occurred first at $14 \mathrm{~min} 25 \mathrm{~s}$ and repeated every $15 \mathrm{~min}$, is caused by the turning on of an additional compressor which causes the suction pressure to decrease suddenly. As the system models the evaporator temperature directly as a function of the evaporator's pressure, an additional compressor turning on will cause an immediate drop in the temperature. Moreover, as the air-on and air-off temperatures cooled via evaporation of the refrigerant into the suction line, the suction pressure increases. Once the display case reaches the lower setpoint, the suction pressure reaches the setpoint for a second compressor to turn on, causing a suction pressure to suddenly decrease; this translates to a sudden drop in temperature of the air-on and air-off temperatures.

From Figs. 9 and 10, both the simulation results and the real data contain 12 full on-off cycles of the expansion valve for a 3 -h period. The simulation expansion valve remains open for $6 \mathrm{~min}$ and $30 \mathrm{~s}$, whilst for the real data, the valve remains open for $4 \mathrm{~min}$ and $42 \mathrm{~s}$. The greater demand on the system explains the difference in the opening time for the expansion valve. Moreover, in Fig. 10, there is a difference in the width of the peaks for some of on-off cycles of the expansion valve, this is due to the sampling rate of real data being $1 \mathrm{sample} / \mathrm{min}$,

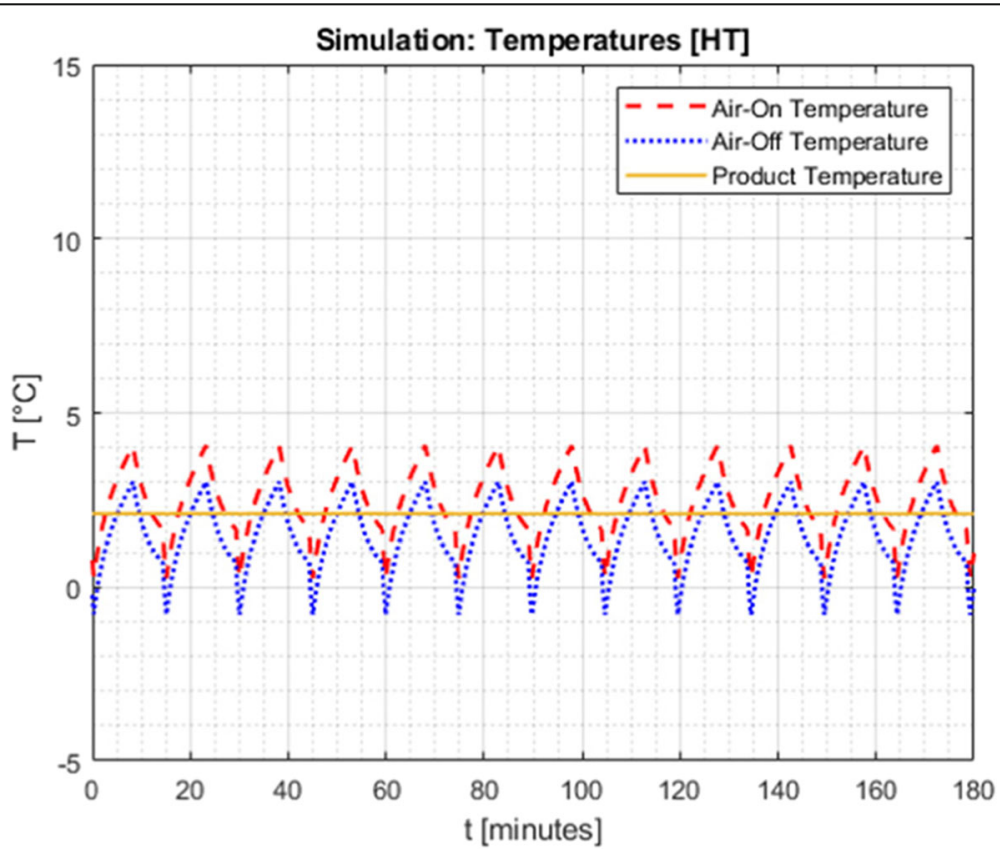

Fig. 7 Simulation of the HT display temperatures for the developed refrigeration system model 


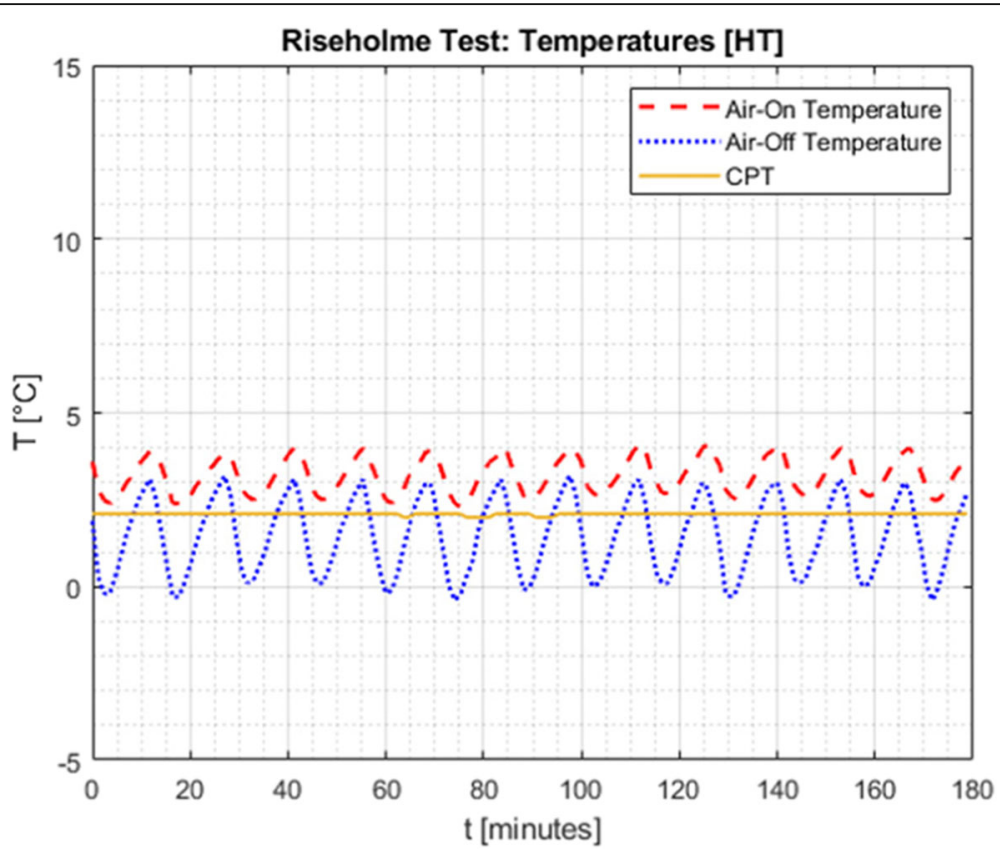

Fig. 8 Real operational data for the HT temperatures of the refrigeration system

which causes a sample value that might be taken whilst the valve is not fully open.

The suction pressure of the refrigeration system for the simulation results of the developed model and for the real data of the Riseholme Refrigeration Centre are shown in Figs. 11 and 12, respectively. The suction pressure for both the simulated model and the real data follow a similar trend. However, there are some differences with the suction pressure over the 3-h period, due to the differences in the size and types of loads at the Riseholme refrigeration system. Both the simulation data and test data had similar maximum values reaching peaks of $374.8 \mathrm{kPa}$ and $373.3 \mathrm{kPa}$, respectively, whilst the minimum values for the simulation and real data were $334.3 \mathrm{kPa}$ and $338.9 \mathrm{kPa}$, respectively. Considering that the setting of the suction line pressure

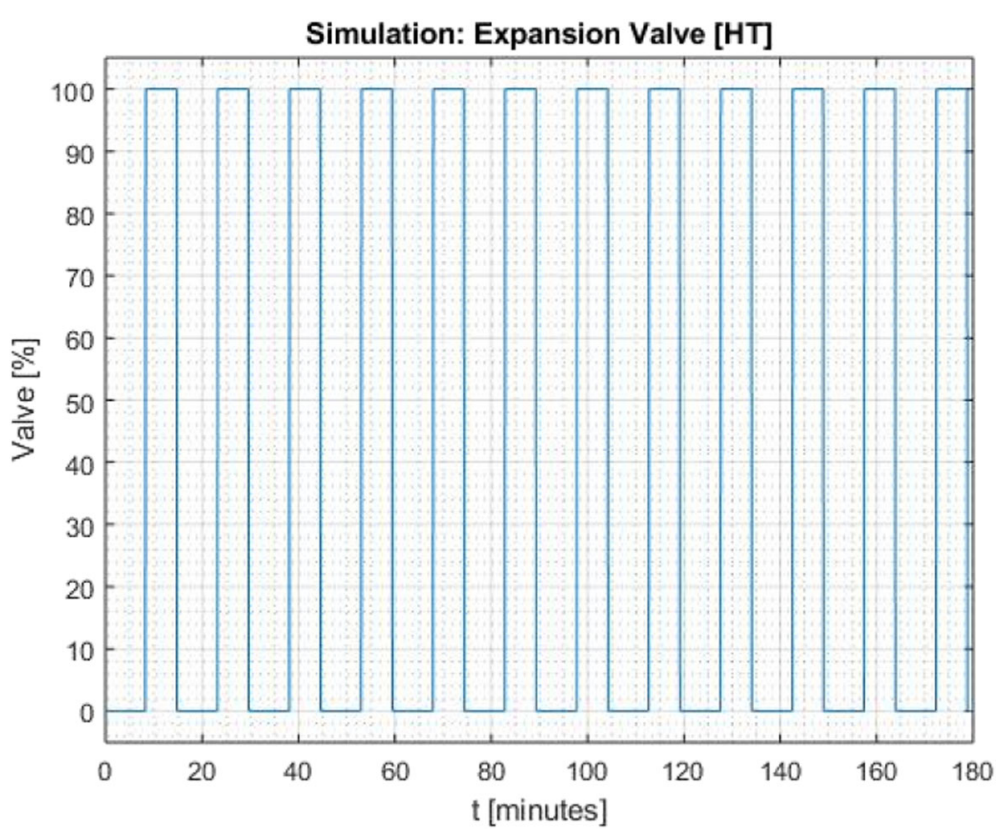

Fig. 9 Simulation of the expansion valve operation for the developed refrigeration system model 


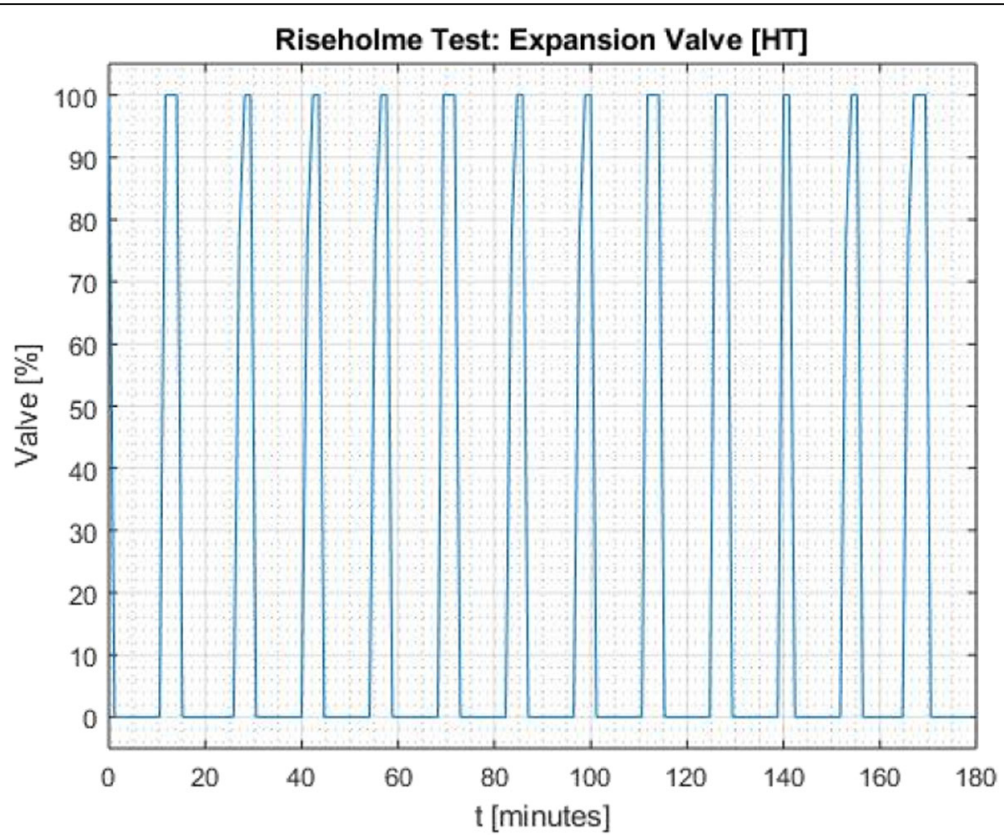

Fig. 10 Real operational data of the expansion valve for the refrigeration system

at the Riseholme Research Centre was sat on $340 \mathrm{kPa}$ (3.4 bar). Therefore, large random fluctuations due to the disturbances caused by the loads and the environment can be eliminated in the simulation process.

The power consumption of the HT system for the simulation result of the developed model and for the real data at the Riseholme Refrigeration Research Centre is shown in Figs. 13 and 14, respectively. It is noticed that there was always at least one compressor running at full capacity, with an additional compressor coming on occasionally when needed. Figure 13 shows the power drawn from the compressors during the simulation; there are 12 instances where an additional compressor kicks in to reduce the suction pressure in comparison

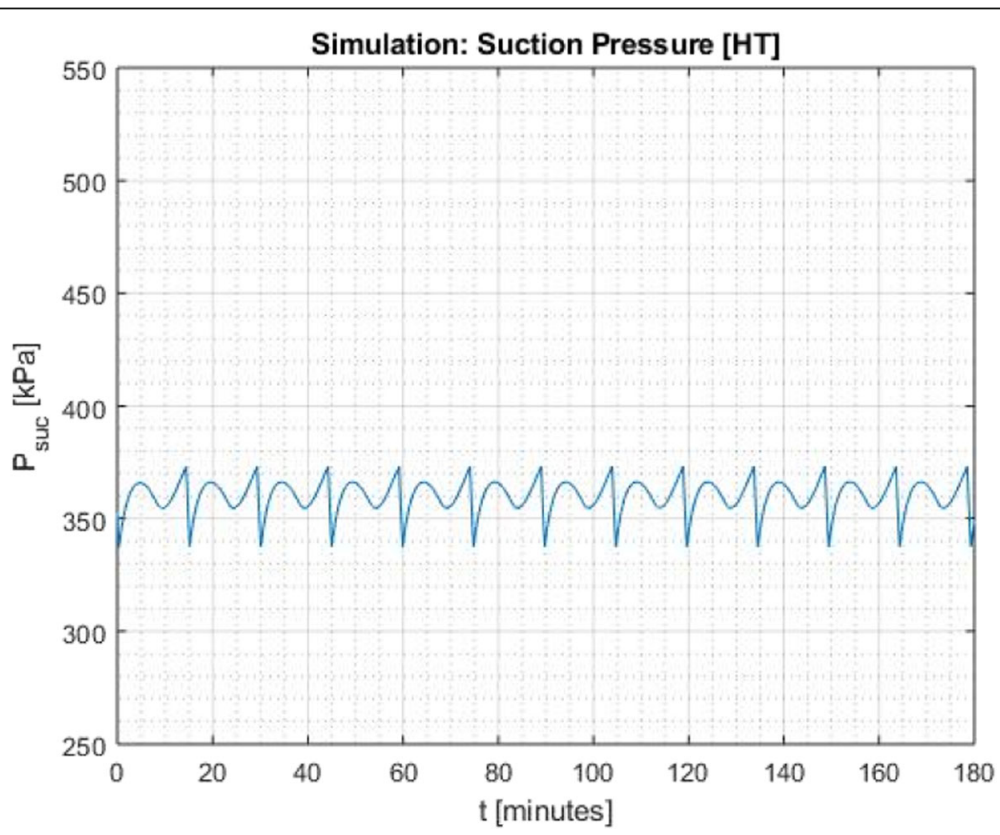

Fig. 11 Simulation of the suction pressure for the high temperature system of the developed refrigeration system model 


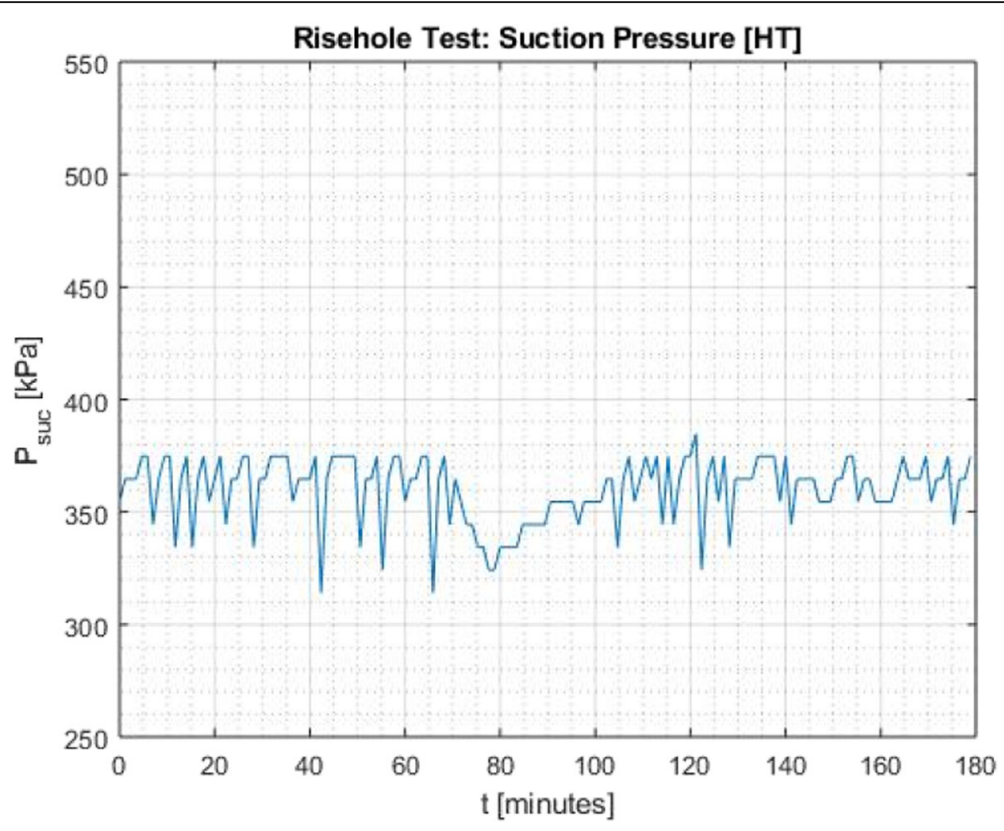

Fig. 12 Suction pressure for the high-temperature system at the Riseholme Refrigeration Research Centre

with 19 instances for the data at the Riseholme Refrigeration Research Centre as seen in Fig. 14. This is due to the modelling of all the display cases as a lump sum; therefore, all cases act in the same way and uniformly throughout the testing period. At the Riseholme Refrigeration Research Centre, there are likely to be bigger changes in the suction line pressure due to the varying behaviour of each display case, resulting in more frequent variations in the suction pressure and therefore more instances for an additional compressor to kick in. Hence, a slight difference in the total energy is drawn by the compressors during the 3 - $\mathrm{h}$ period, with the model simulation consuming a total of $17.25 \mathrm{kWh}$ and the Riseholme Refrigeration Research

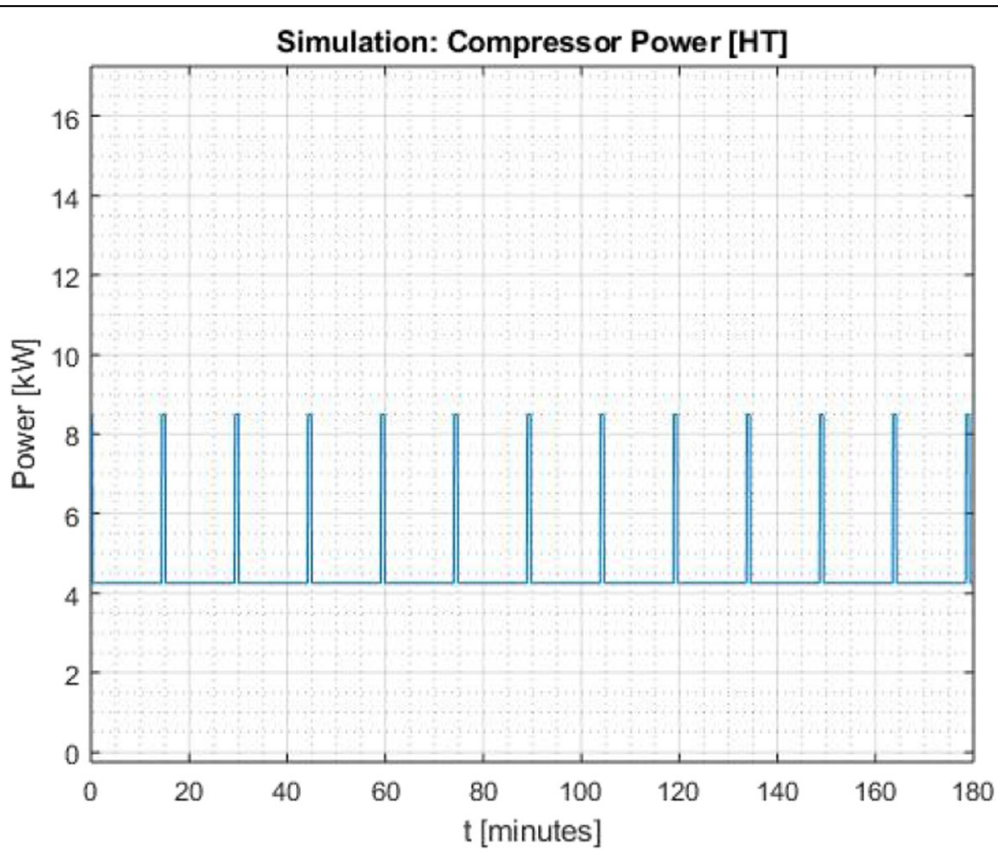

Fig. 13 Simulation of the power consumption for the HT compressors of the developed refrigeration system model 


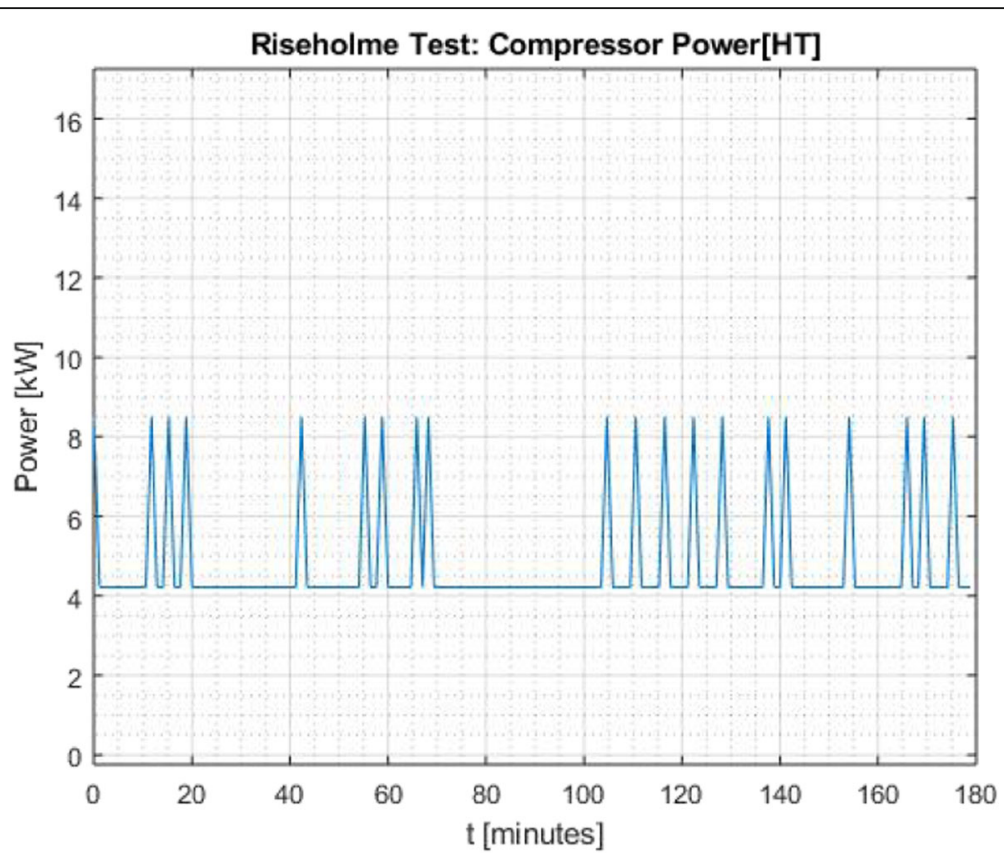

Fig. 14 Power consumption for the HT compressors at the Riseholme Refrigeration Research Centre

Centre consuming $14.18 \mathrm{kWh}$ as shown in Figs. 15 and 16, respectively, where the area under the curve represents the energy consumed per hour up to $3 \mathrm{~h}$.

From Figs. 15 and 16, the Riseholme data demonstrates more power drawn due to the higher occurrence of a second compressor turning on. However, due to the Riseholme system logging data every minute compared to the simulation process which logs data every second, hence samples were omitted when the second compressor is running; this ultimately reduces the total power drawn. Reducing the sampling rate for the simulations would reduce the error; however, for the following simulations, a larger sampling rate was

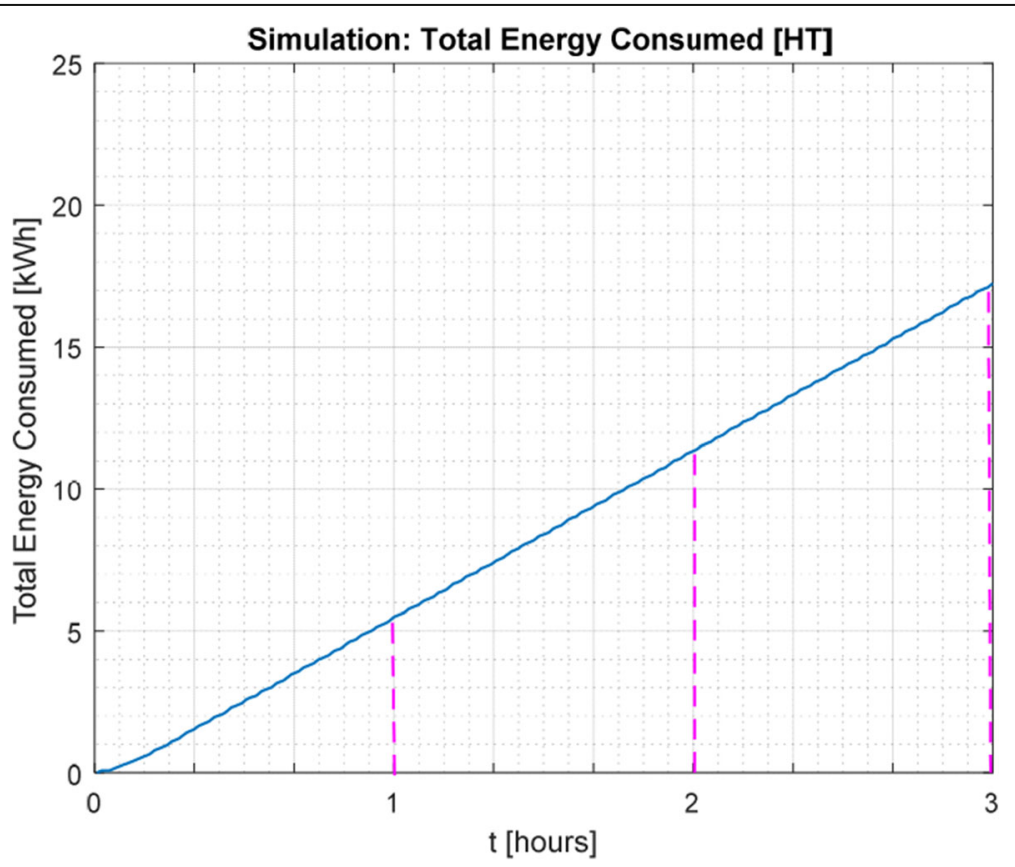

Fig. 15 Total energy consumption for the HT compressors of the developed refrigeration system model 


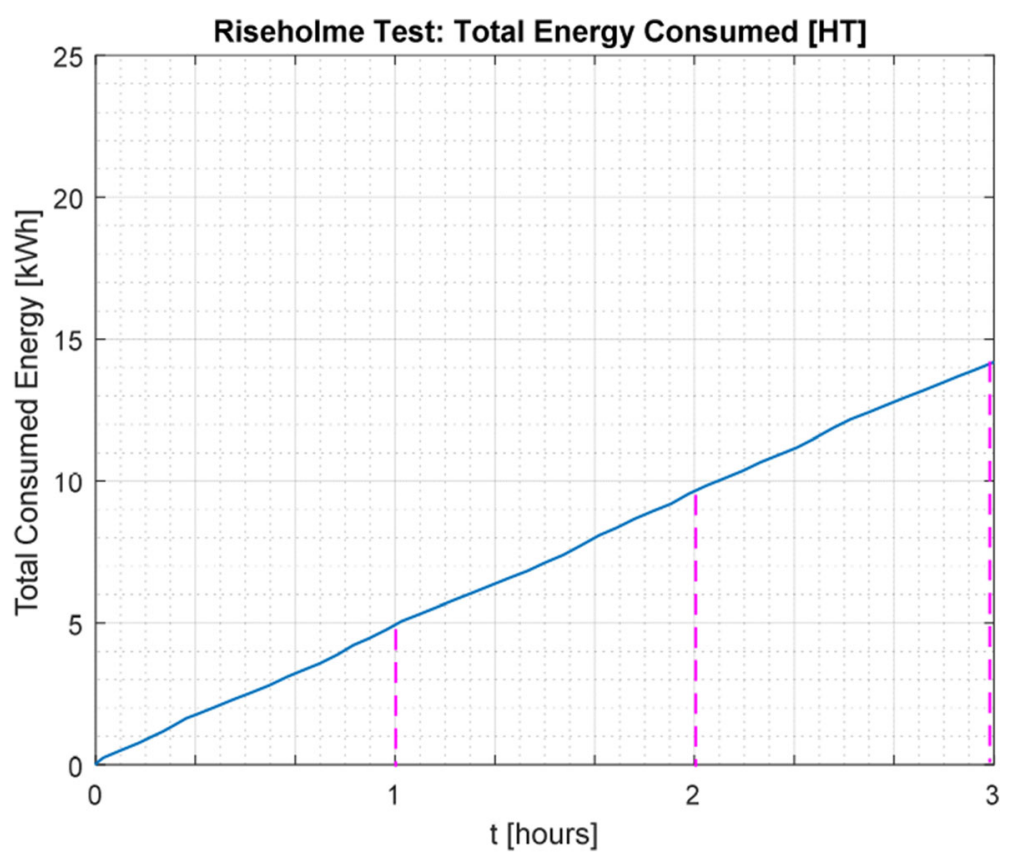

Fig. 16 Total energy consumption for the HT compressors at the Riseholme Refrigeration Research Centre

selected as it increases the accuracy of the data and gives a higher resolution for the system behaviour. It is noticed that the trends of the simulation results for the display case temperatures, expansion valve opening degree, suction line pressures and compressors power consumption have high resemblance to the trends of the collected data obtained from the Riseholme Refrigeration Research Centre. This supports the validation of the developed model.

\section{Investigating the impact of indoor temperature on the performance of the commercial refrigeration system}

Commercial supermarkets employ various systems in order to create a comfortable controlled environment inside the store for the customers and non-refrigerated products. Air-conditioning (AC) systems are the most common which aim to control the internal temperature and humidity. Having the store temperature regulated by a separate AC system will reduce fluctuations and overall load on the refrigeration system, resulting in a higher degree of optimisation and therefore reduction in energy consumption. Consequently, if the AC system fails or experiences declined performance, the energy consumption of the refrigeration system can be drastically affected [43]. Due to the various heat emitting systems and activities within a commercial supermarket and in case of an AC system failure, the store temperature is expected to rise until a saturation limit is reached, where the heat transfer into the store environment is the same as the heat transfer out [43]. In this research, a gradual AC system failure, a sudden failure and an intermittently faulty AC will be investigated.

\subsection{Gradual failure of AC system}

The gradual failure of the AC system is simulated as if the performance is greatly reduced and so cannot maintain the required temperature. For simplification, the gradual rise in store temperature is assumed to be linear during the simulated 3-h period. This is not likely to be fully accurate, as the exact store conditions are not known under these circumstances. Furthermore, this is not likely to be a smooth profile and will be affected by slight fluctuations caused by other external factors such as drafts, location in the store and variations in outdoor temperatures. Additionally, due to Newton's law of cooling which states that as the temperature of two bodies become closer together, the rate of heat transfer between them will decrease [44]. This means that the temperature profile should initially rise at a steeper gradient then plateau. Since this effect is very minimal, a linear trend can be used to simulate the profile with little discrepancy in results. The temperature profile of the store was set to rise linearly from 20 to $28^{\circ} \mathrm{C}$ over the 3 $\mathrm{h}$ period in order to simulate the decline performance of the AC system, as shown in Fig. 17. These values were selected to simulate a typical hot summers day in the UK and therefore produce results which would feature considerable impacts. Accordingly, the HT case 


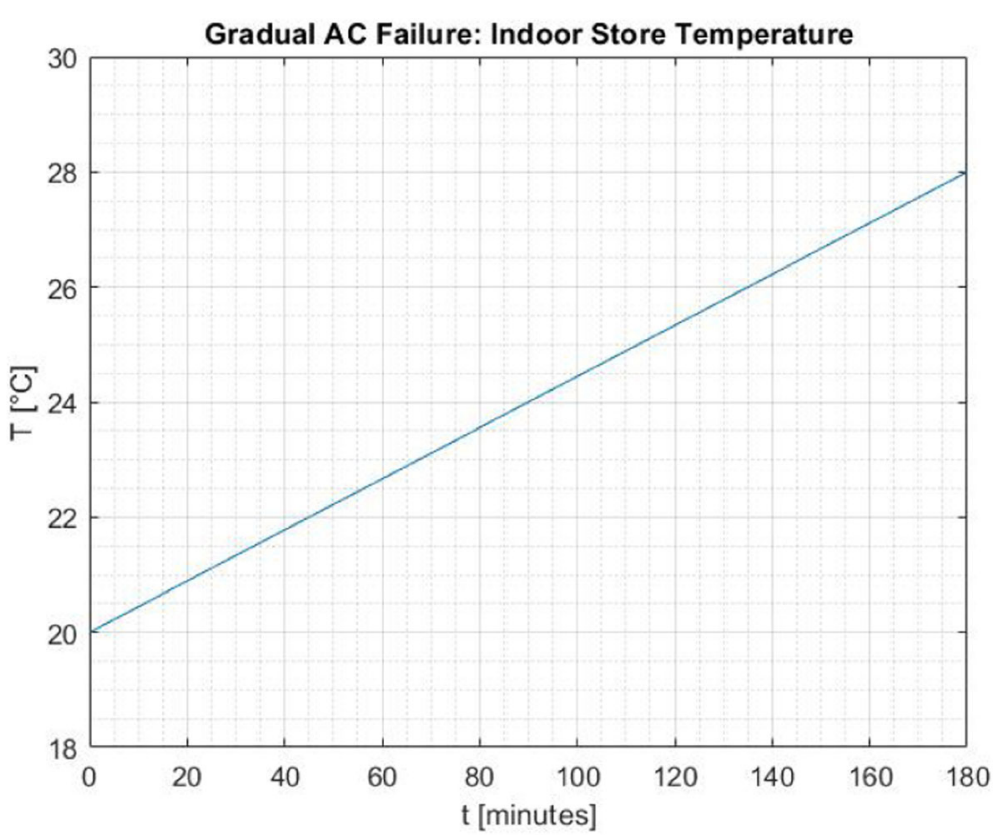

Fig. 17 Indoor store temperature during gradual AC failure

temperatures, opening degree of the expansion valve, suction pressure, compressors power and total energy consumed during this simulation are shown in Figs. 18, $19,20,21$, and 22 , respectively.

From Fig. 18, the temperature of the products is relatively unaffected by the failure of the $\mathrm{AC}$ system and subsequent rise in store temperature. However, the airon and air-off temperatures show considerable fluctuations and hence impact their time cycles (time between the minimum and maximum temperatures/expansion valve opening and closing) as the increase temperature progresses. The fluctuation in air-on will lead to a fluctuation in air-off temperature associated with a fast-dynamic behaviour of the suction pressure. This occurrence is further supported by the fluctuations becoming less frequent as the suction pressure slows

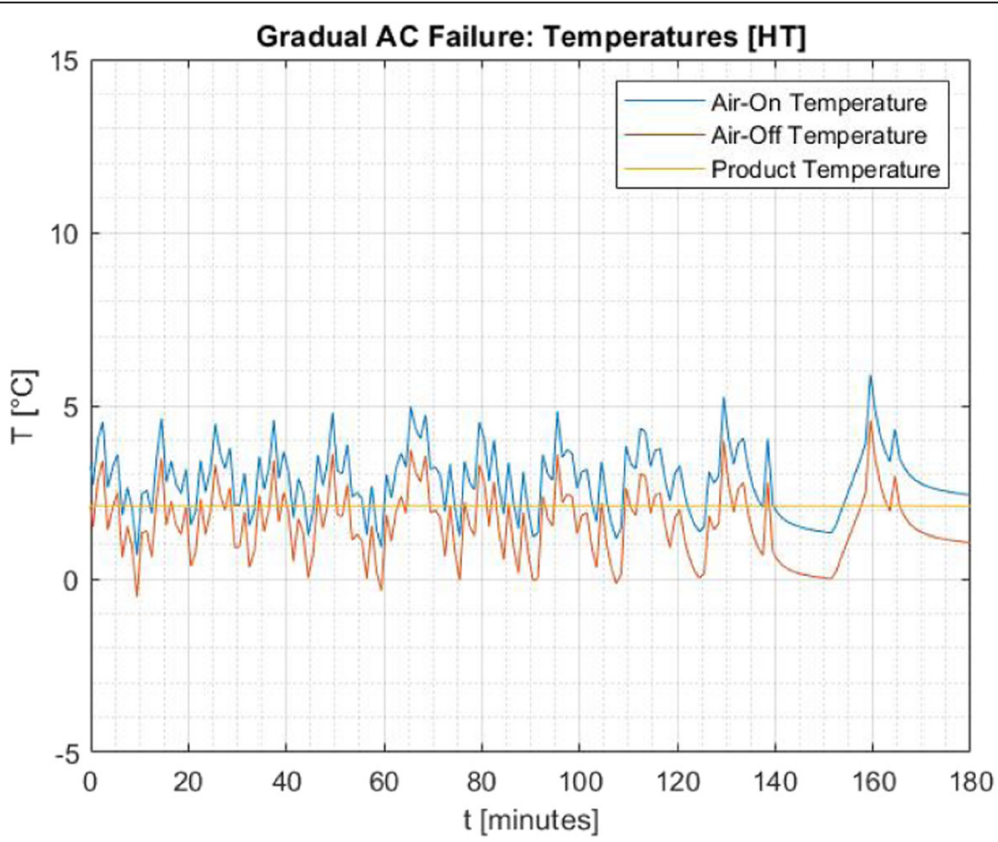

Fig. 18 High-temperature HT case temperatures during gradual AC failure 


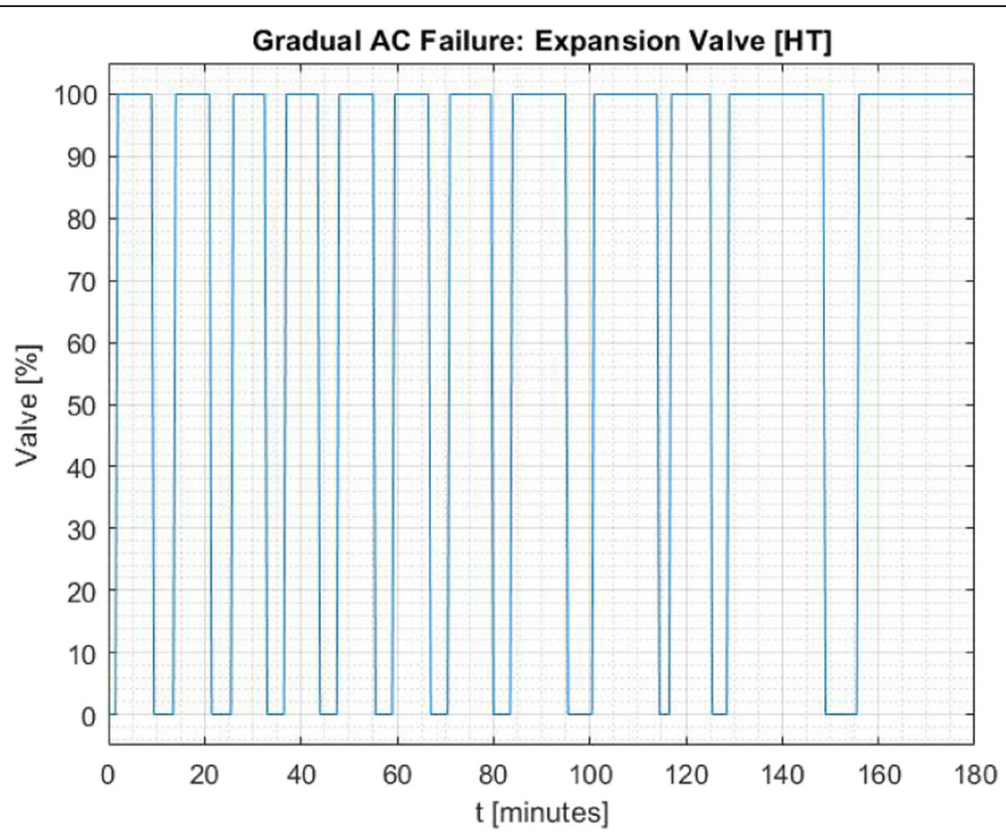

Fig. 19 Expansion valve opening degree for the HT case during gradual AC failure

down towards the end of the simulation. Furthermore, Fig. 19 also supports the observation that the time cycle increases as the simulation and store temperature increase, in order to allow more refrigerant into the evaporator, hence causing an increase in the flow rate into the suction line which in turn increases the pressure. Furthermore, as the simulation time increases and, more importantly, store temperature, the rate of increase in suction pressure following the opening of the expansion valve becomes larger. As the flow rate of refrigerant into the suction line is increased, more compressors have to turn on to meet demand. This results in the duty cycle of the compressors becoming larger and therefore causes more power consumption. Figure 21 shows the compressor power during the 3-h period. As time increases, the frequency of the second

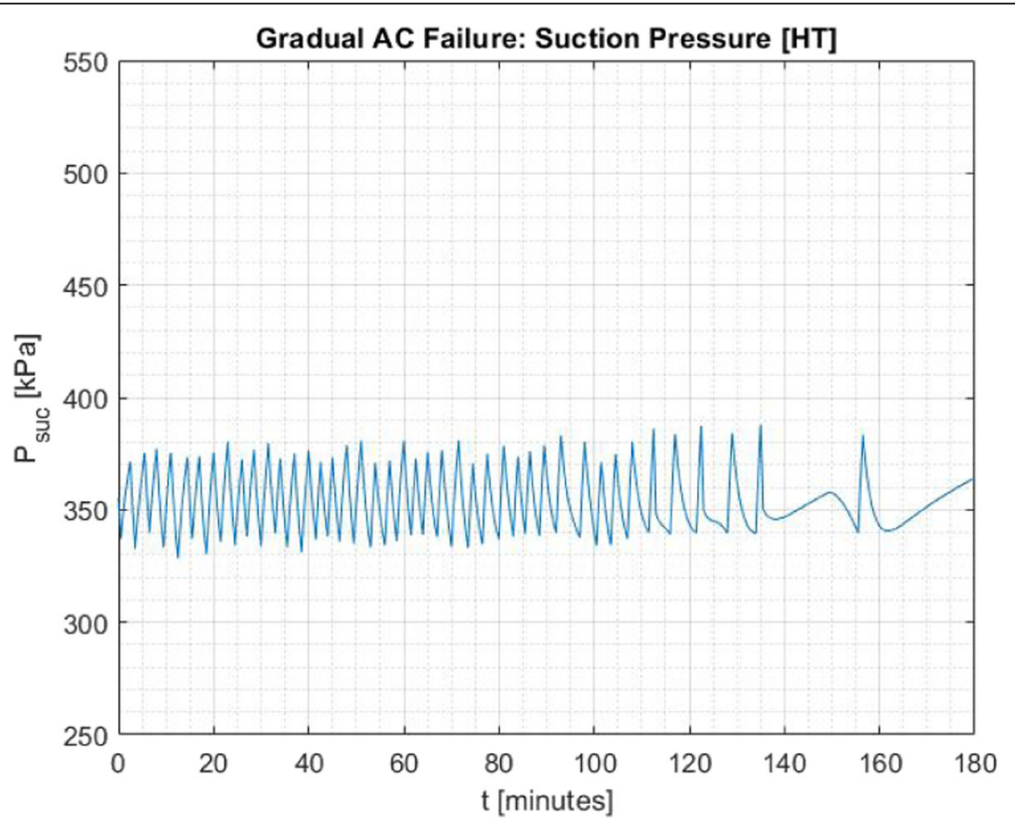

Fig. 20 Suction pressure for the HT system during gradual AC failure 


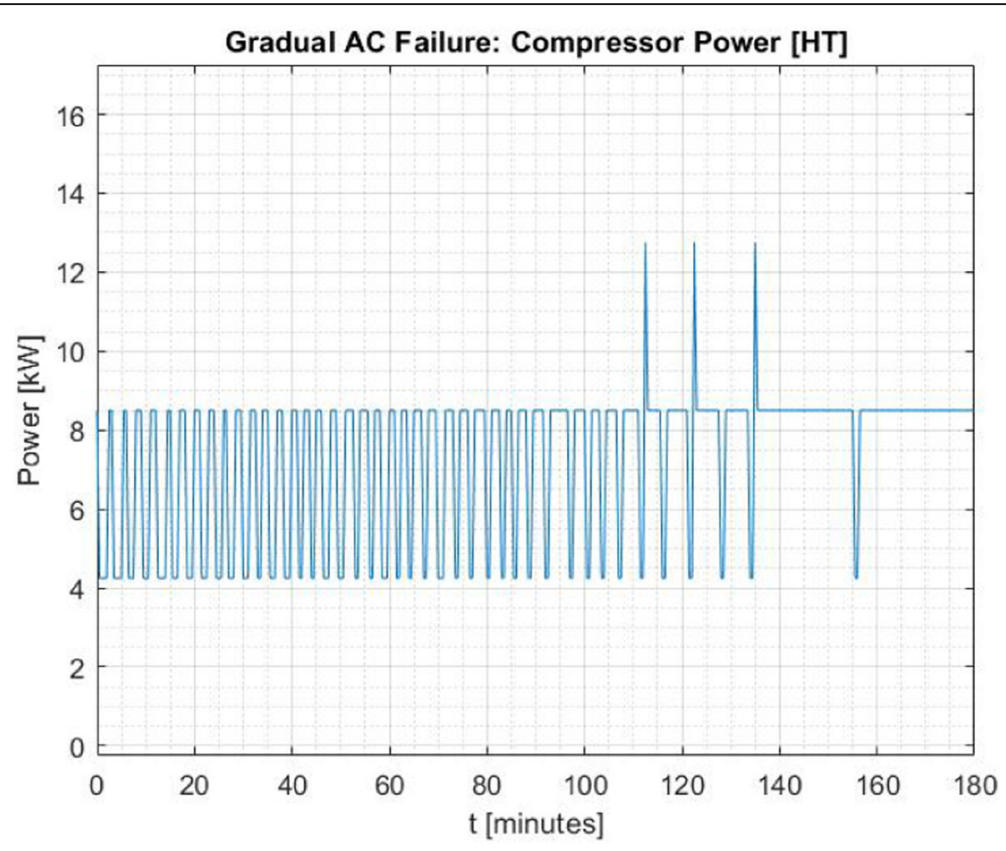

Fig. 21 Compressor pack power for the HT system during gradual AC failure

compressor to turn on becomes more recurrent until it is more or less turned on consistently. As time further progresses, eventually a third compressor starts to come on. The rate at which the power consumption increases can therefore be seen to rise with the store temperature. Comparing Figs. 16 and 22 shows a $3 \mathrm{kWh}$ increase in total energy consumption by compressors pack, at $17.25 \mathrm{kWh}$ for normal AC operation and $20.26 \mathrm{kWh}$ for gradual AC failure condition.

\subsection{Sudden failure of AC system}

A drastic failure of the $\mathrm{AC}$ system which results in the rise of store temperature being steeper initially but then

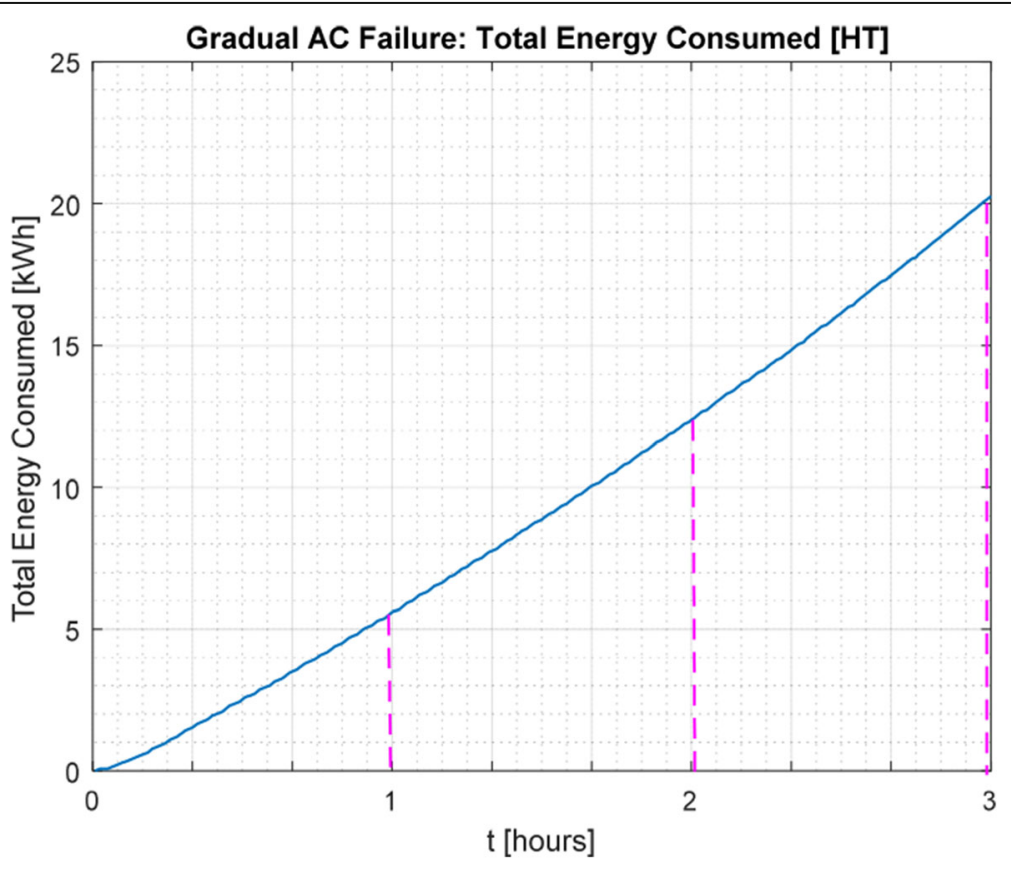

Fig. 22 Total energy consumed for the HT system during gradual AC failure 


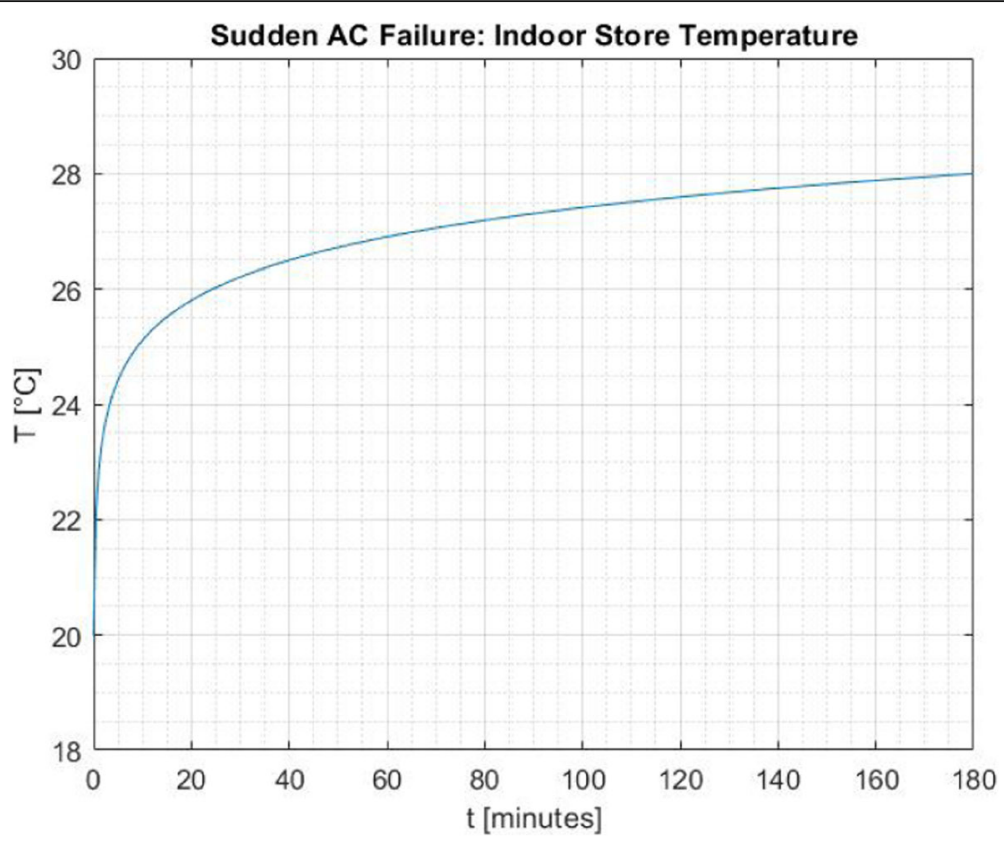

Fig. 23 Indoor store temperature during sudden AC failure

levels off as the overall net heat transfer becomes zero. The store temperature profile is shown in Fig. 23 is modelled from 20 to $28^{\circ} \mathrm{C}$ over a 3-h period using natural logarithms. It is assumed that the majority of the temperature increase would happen within the first 20 min of the simulation and then gradually plateau thereafter. During a hot summer's day, the temperature rapidly increase within a short time frame until stable conditions are achieved and no net heat transfer can occur. Consequently, the HT case temperatures, opening degree of the expansion valve, suction pressure, compressor power and total energy consumed during this simulation are shown in Figs. 24, 25, 26, 27, and 28, respectively. From Fig. 24, the product temperatures remain unaffected throughout the drastic failure of the AC system. The air-on and air-off

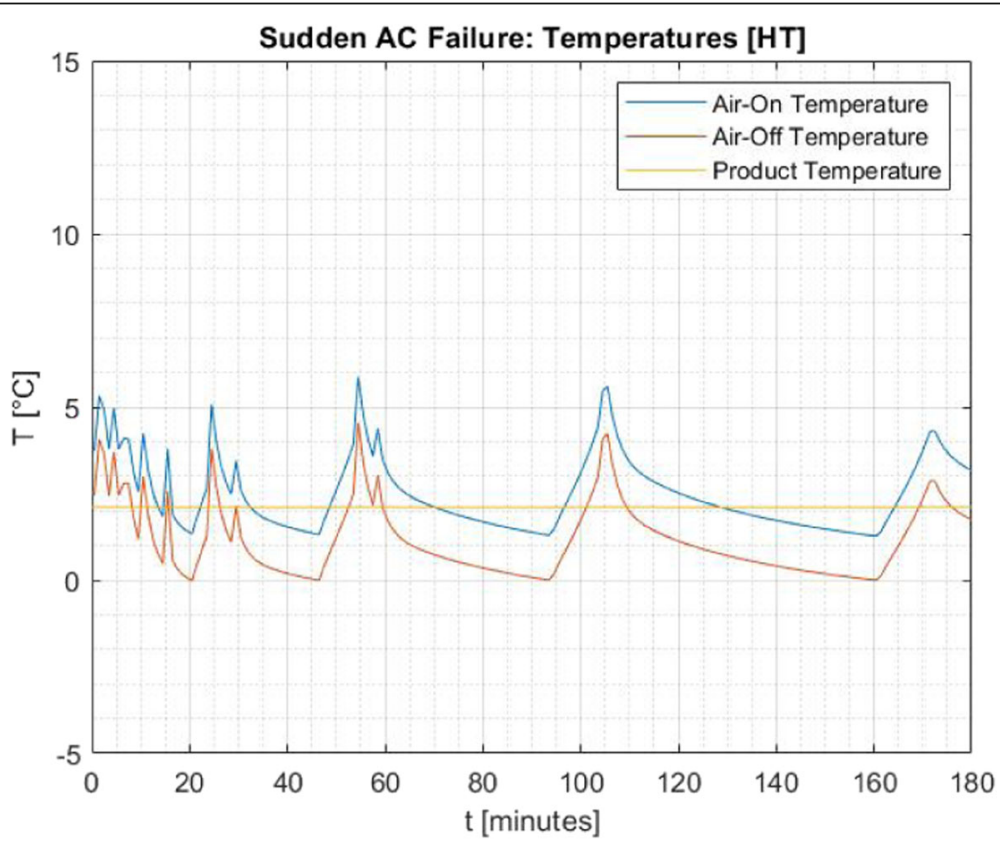

Fig. 24 High-temperature $(H T)$ case temperatures during sudden AC failure 


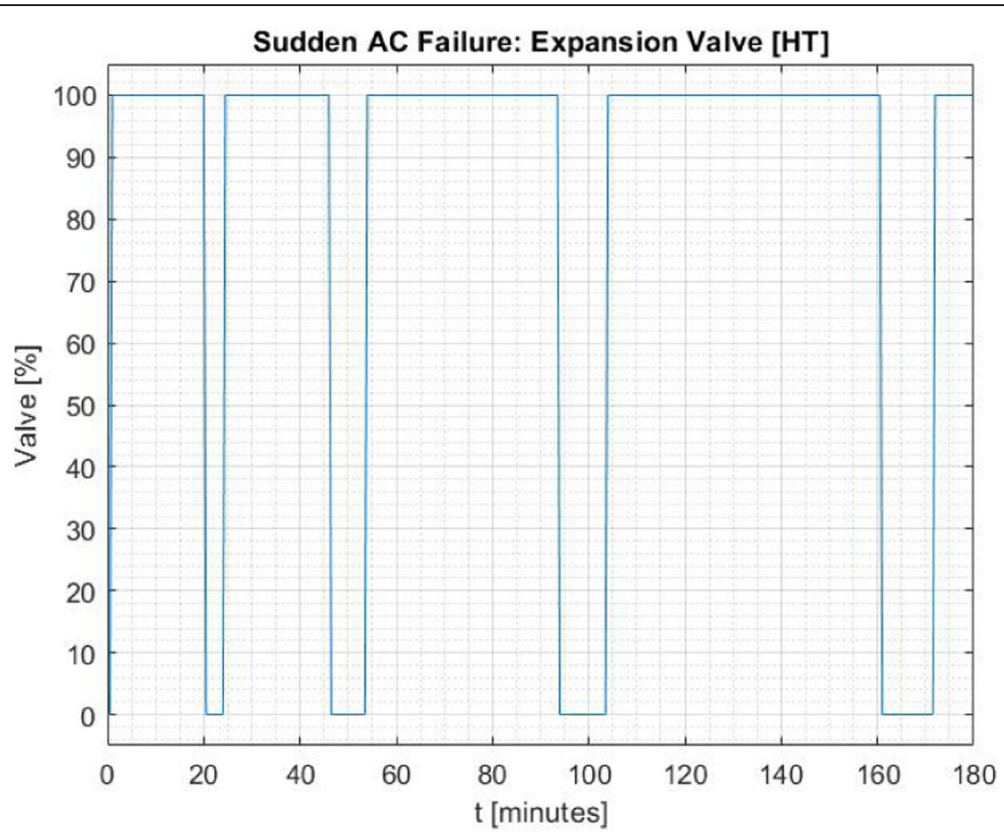

Fig. 25 Expansion valve opening degree for $\mathrm{HT}$ case during sudden AC failure

temperatures, after the initial rapid increase in indoor store temperature, from 20 min onwards the temperatures become less dynamic and cycles begin to get consecutively longer. The same can be noticed regarding the expansion valve cycling times and suction pressure dynamics as shown in Figs. 25 and 26, respectively. As the store temperature increases, the heat load in the HT cases increase; hence, the time for the suction pressure to reach the setpoints increases and the opening time for the expansion valves increase as well. After the initial surge, as the temperature is gradually increasing still, the demand remains high and therefore results in more compressors being required to turn on. As the temperature begins to decrease, the system begins to act less dynamically and overall acts significantly slower. At

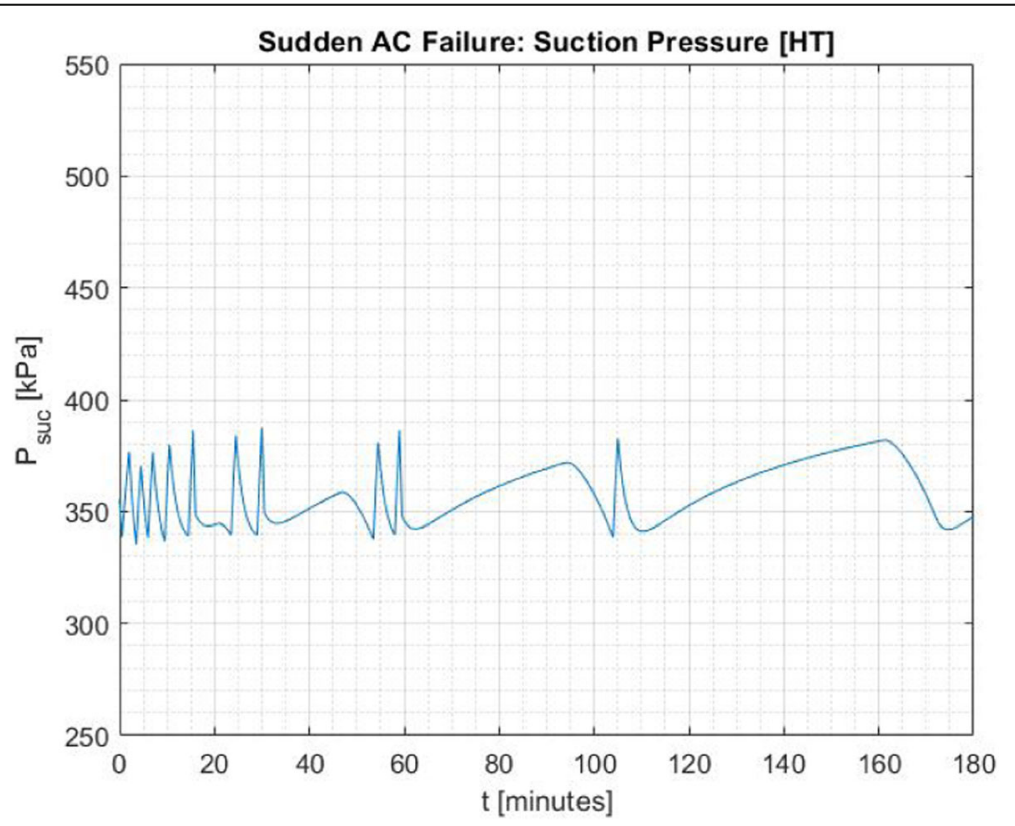

Fig. 26 Suction pressure for HT system during sudden AC failure 


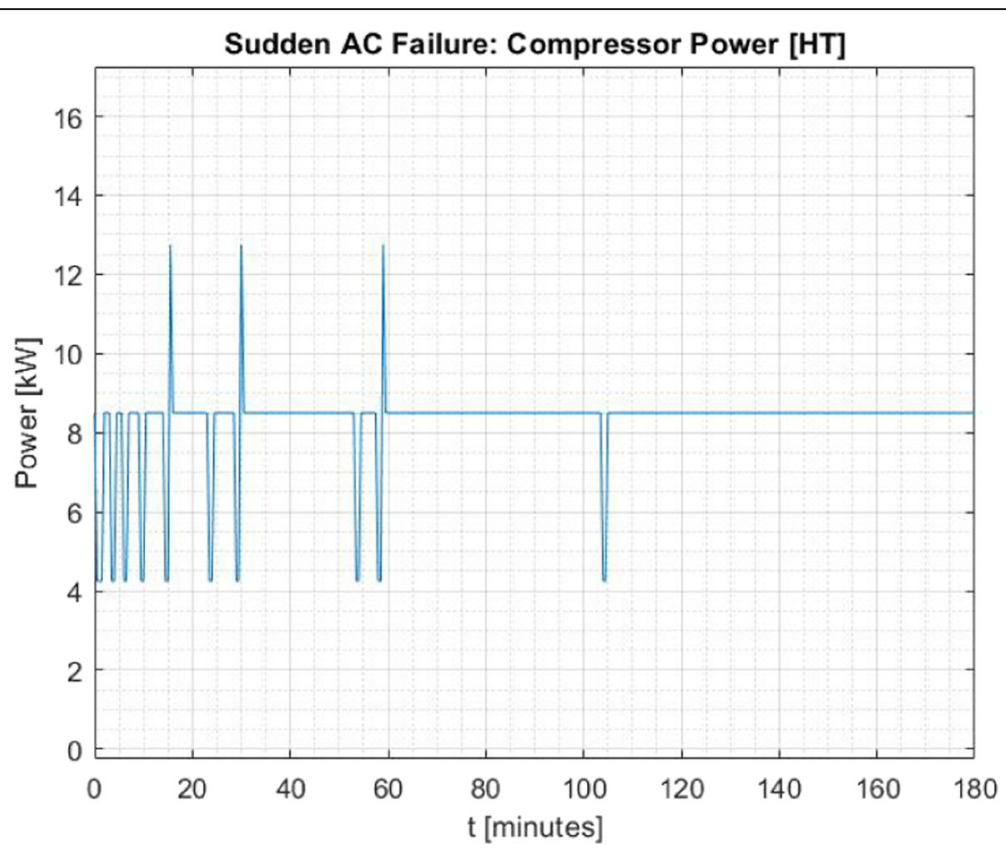

Fig. 27 Compressor pack power for HT system during sudden AC failure

minute 60 and onwards, there are occasional spikes in the suction pressure, and subsequently the air-on and air-off temperatures, which is caused by the need for the expansion valve to open. The system can be said to be reaching a stable state resulting in little fluctuations amongst parameters and beginning to function at the new condition. The system is likely to be unable to increase its operational performance anymore and therefore reached its maximum cooling capacity.

Figure 27 shows the power drawn from the HT compressor pack, which shows that once the system has stabilised following the sudden drastic increase in temperature, the compressors fluctuate on and off slowly resulting in little variation in power drawn away

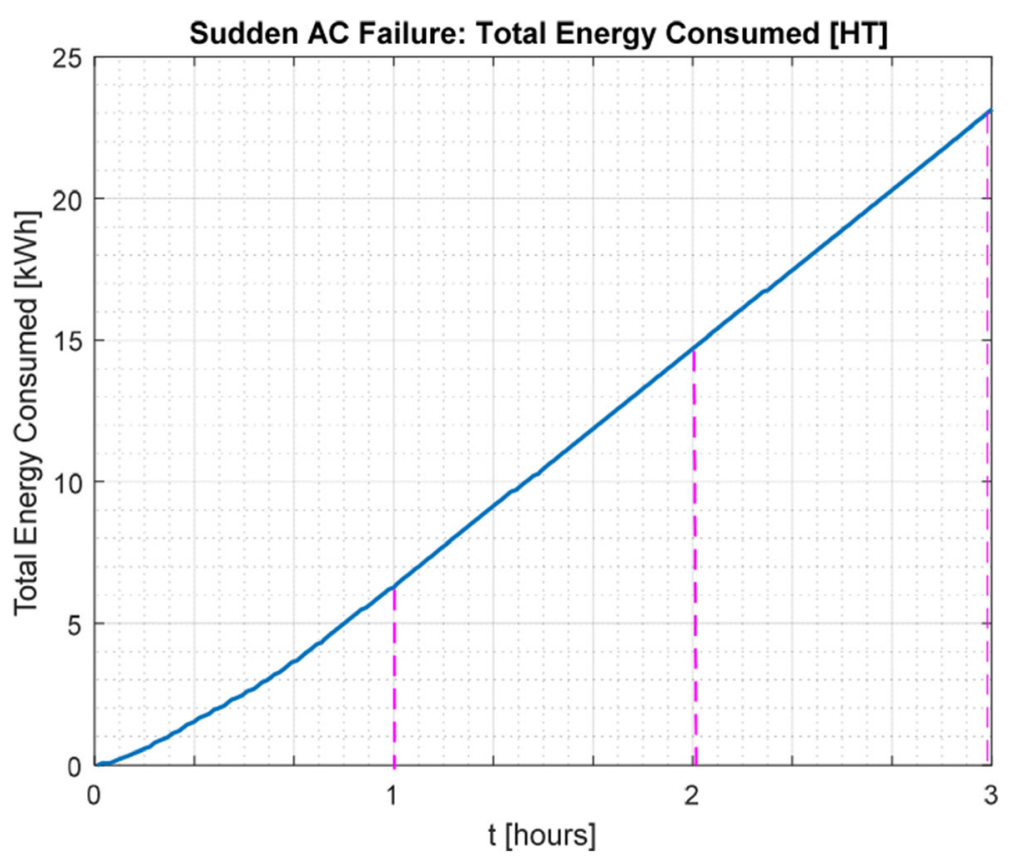

Fig. 28 Total energy consumed for HT system during sudden AC failure 
from $8.5 \mathrm{~kW}$. It can be seen that for the majority of the 3 -h period, the 2 compressors were on and consumed $8.5 \mathrm{~kW}$, with a third compressor kicking on at 3 instances and a single compressor turning off at 10 instances leaving one compressor on.

Compared to the gradual failure, the sudden failure creates a higher temperature profile in the store which consequently causes a higher demand on the evaporator, prolonging the opening of the expansion valve whilst increasing the suction line pressure. This triggers an increase in the number of compressors being used to maintain the desired suction line pressure and results in more power drawn.

Comparing Figs. 16 and 28 shows approximately $5.81 \mathrm{kWh}$ increase in total energy consumption by compressors pack, at $17.25 \mathrm{kWh}$ for normal AC operation and $23.06 \mathrm{kWh}$ for sudden $\mathrm{AC}$ failure condition.

\subsection{Intermittent fault of AC system}

This investigation considers the impact of a faulty $\mathrm{AC}$ system which experiences intermittent failure, where the AC system being intermittently operable then inoperable, or operable with reduced performance and so the AC system is referred to as faulty. It is assumed that the indoor temperature of the store would vary between the limits of $20^{\circ} \mathrm{C}$ and $24^{\circ} \mathrm{C}$. To simplify this, it has been assumed that the change in temperature happens instantaneously. This is modelled by using a random number block in Simulink using the average of $20^{\circ} \mathrm{C}$ and a variance of $10^{\circ} \mathrm{C}$ which sampled every $2 \mathrm{~min}$ and had saturation limits of $20^{\circ} \mathrm{C}$ and $24{ }^{\circ} \mathrm{C}$ applied to it. Figure 29 shows the resultant store temperature profile. Consequently, the HT case temperatures, opening degree of the expansion valve, suction pressure, compressor power and total energy consumed during this simulation are shown in Figs. 30, 31, 32, 33, and 34, respectively.

From Fig. 30, it can be seen that the product temperature is minimally impacted by the fluctuations in store temperature caused by the faulty $\mathrm{AC}$ system. The air-on and air-off temperatures show considerable rapid fluctuations, with higher peak temperatures when compared to normal operating conditions. It is clear that the frequent fluctuations in air-on and air-off temperatures presented in Fig. 30 can be explained as a result of the rapid changes in the suction pressure. The impact of the store temperature fluctuations on the expansion valve is shown in Fig. 31, where periods of elevated store temperature correspond with the expansion valve being opened until the temperature of the air-off probe falls to the lower setpoint. Figure 32 shows the suction pressure during the 3-h period shows that the frequent change in store temperature has caused rapid variations in the suction pressure. Additionally, as the AC system is intermittently turning on and off, the suction pressure has not enough time to settle and reach a steady state.

From Figs. 29 and 31, it can be seen that during the extended periods of elevated indoor store temperatures, the duty cycle of the expansion valve increases. This is due to the system requiring a greater cooling capacity and therefore a larger mass of refrigerant. The rapid change in the external heat loads on the system, caused

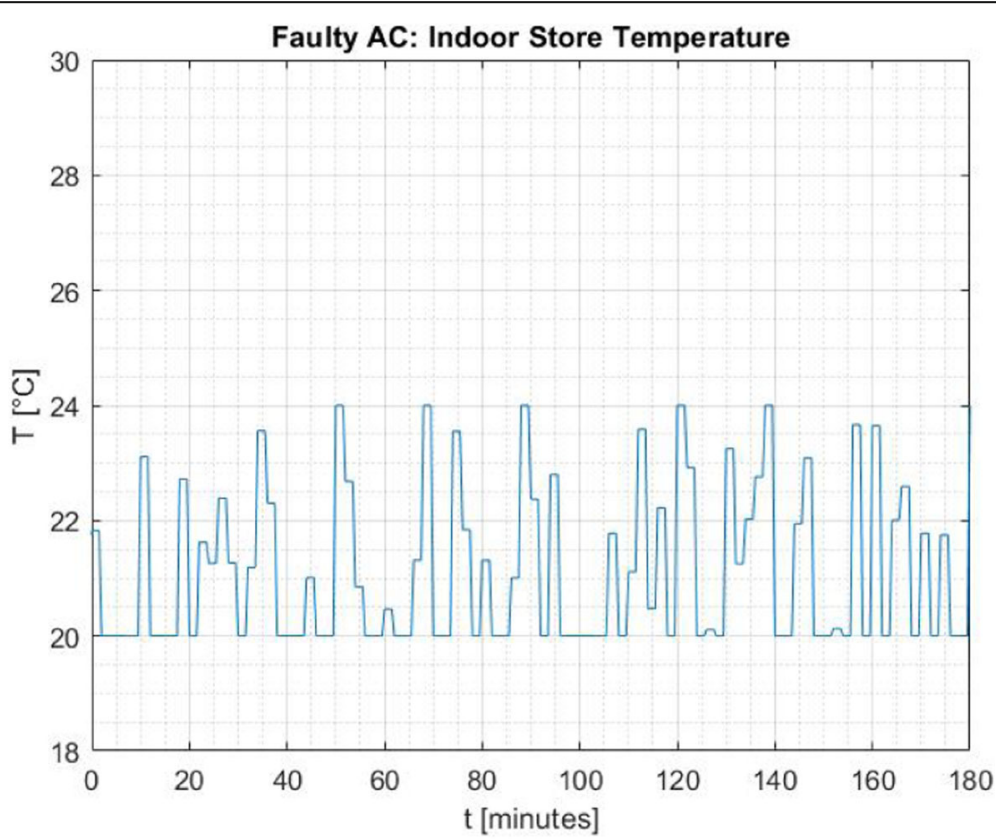

Fig. 29 Indoor store temperature during faulty AC system 


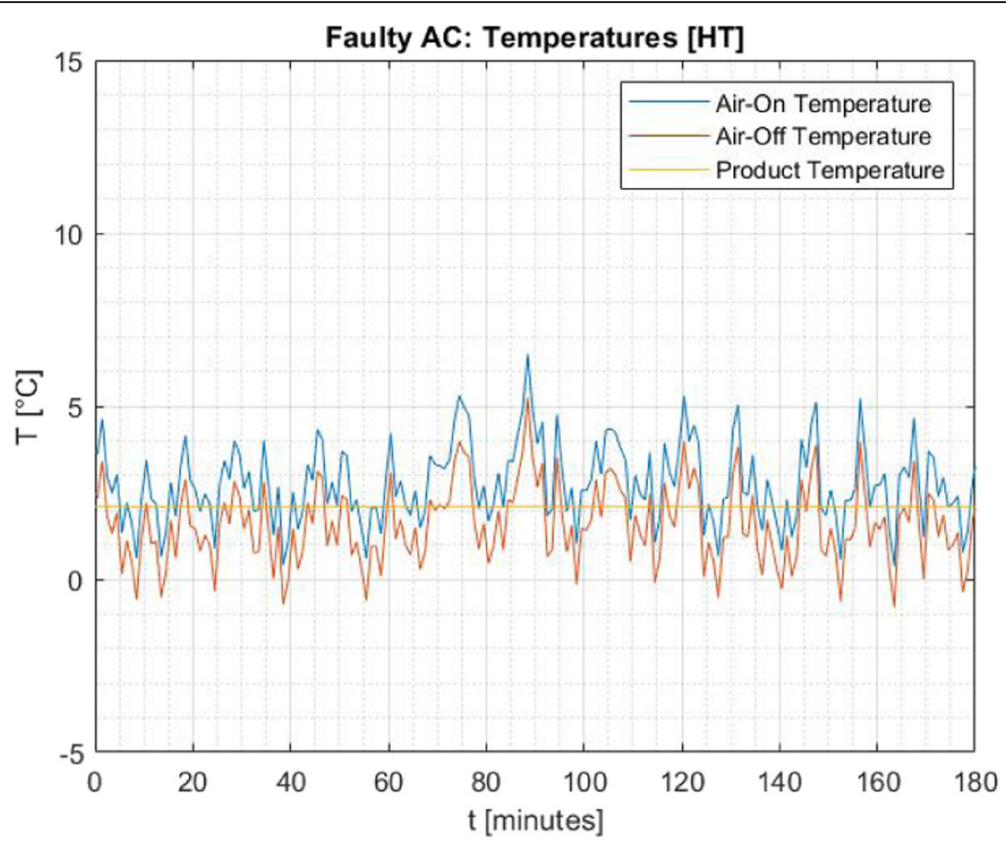

Fig. 30 High-temperature $(H T)$ system case temperatures during faulty $A C$ system

by the random nature of the indoor store temperature, leads to fast and frequent increases in demand for refrigerant, which therefore increases the pressure in the suction line. This increased pressure triggers a second compressor to switch on until the pressure setpoint is reached as can be seen in Fig. 33, which represents the power drawn by the compressors pack. As the increase in temperature is often small, however, the amount of refrigerant required is only enough to increase the pressure to where two compressors are required. This rapid increase in pressure is responsible for the frequent turning on and off of a second compressor which may degrade the operational life of the compressors. It can also be seen that only two compressors are operated due to the lower peak store temperatures experienced during this type of AC failure.

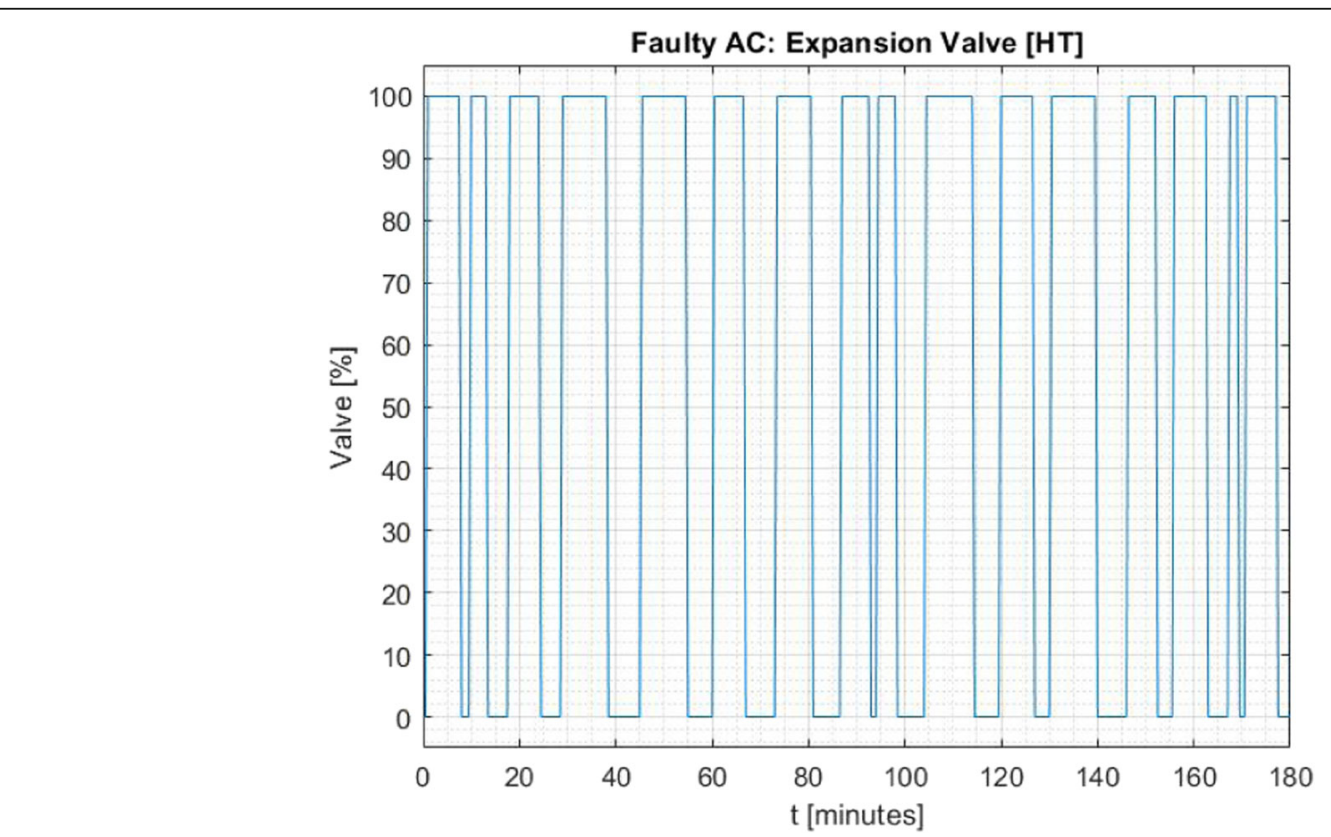

Fig. 31 Expansion valve opening degree for the HT case during faulty AC system 


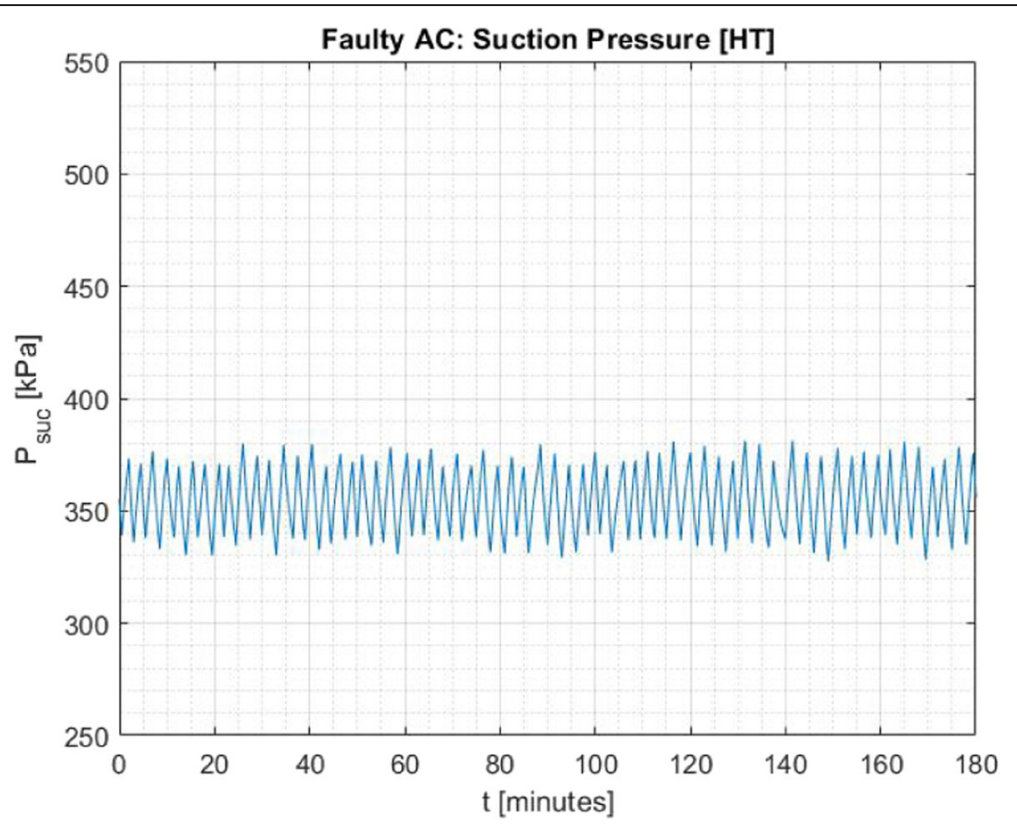

Fig. 32 Suction pressure for the HT system during faulty AC system

Comparing Figs. 16 and 34 shows approximately 0.92 $\mathrm{kWh}$ increase in total energy consumption by compressors pack, at $17.25 \mathrm{kWh}$ for normal AC operation and $18.17 \mathrm{kWh}$ for intermittent $\mathrm{AC}$ failure condition.

The AC failure resulted in a rise in store temperature; this subsequent rise in store temperature inherently caused the heat load on the display cases to increase and therefore dictated the additional requirement of refrigerant mass in the evaporator to maintain the desired temperatures within the display cases. The increased flow rate into the suction line, causing the increased rate of change of suction pressure, therefore required more compressors to be running with increased duty cycle in order to keep the suction pressure within the

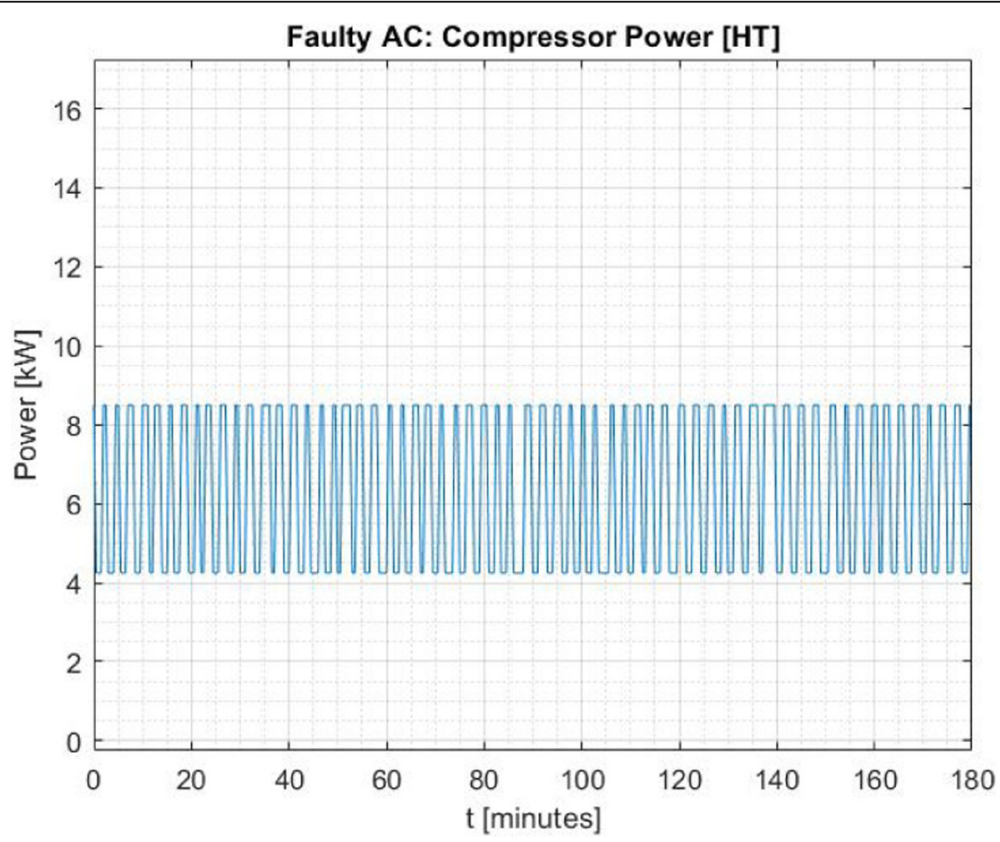

Fig. 33 Compressor pack power for the HT system during faulty AC system 


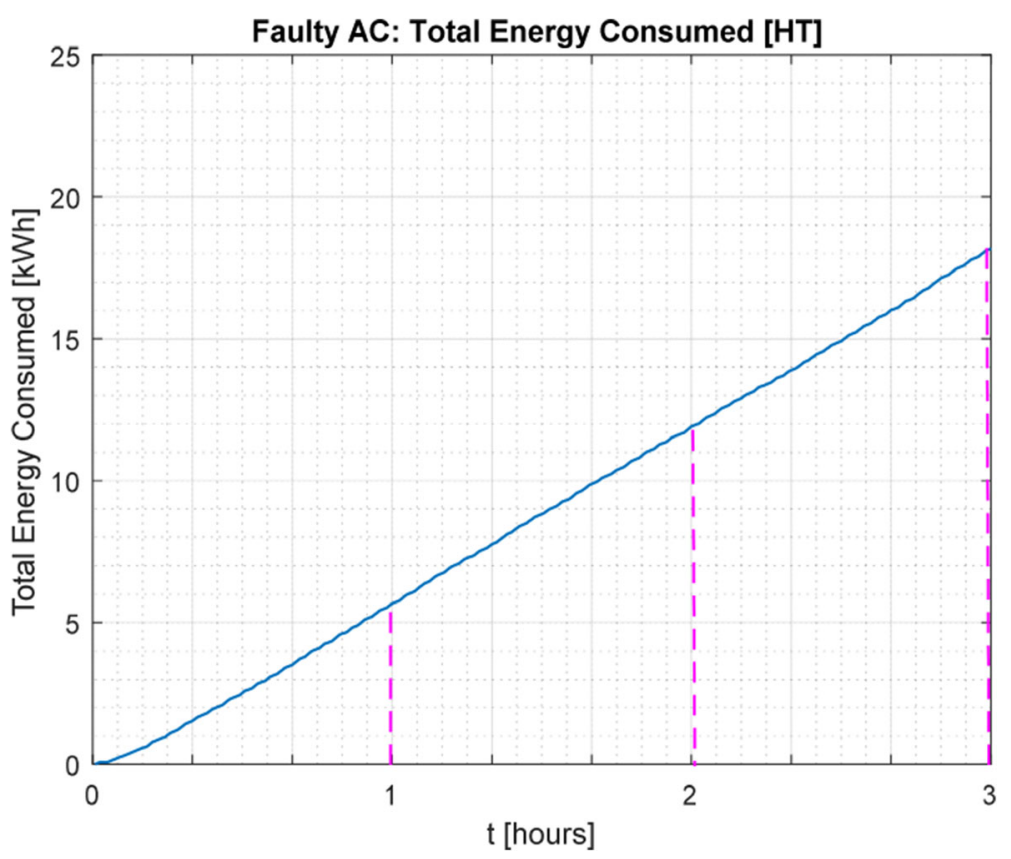

Fig. 34 Total energy consumed for the HT system during faulty AC system

desired range. This ultimately caused the power consumed to increase.

It is notable that for all three failure types, the product temperature experiences no noticeable fluctuations and remains comfortably within the temperature boundaries between 3 and $1{ }^{\circ} \mathrm{C}$. This shows that during these types of faults, and given the chosen temperature limits, food safety remains uncompromised as the system is able to provide adequate cooling. All three failure types also showed that an increased store temperature caused by a failing AC system leads to greater power consumption as the system requires greater cooling capacity. Compared to the normal AC operation, the gradual failure consumed a further $3 \mathrm{kWh}$ during a 3-h period, yielding a $17.4 \%$ increase. The sudden failure consumed $5.81 \mathrm{kWh}$ of $33.6 \%$ increase. The intermittent fault increased by $0.92 \mathrm{kWh}$ of $5.3 \%$ increase. Overall, the AC failures caused the power drawn to increase due to spending a prolonged period of time at higher temperatures than during the normal AC operation. Additionally, the frequency which the compressors switch on and off increases the level of wear on the compressors. Both gradual and sudden failures of the AC system show that a sustained increase in temperature leads to a greater duty cycle for the expansion valve to increase the amount of refrigerant available. It is found that the sudden failure of the AC system had the greatest impact on the system. As the temperature of the store rises quickest, the display cases are exposed to higher temperatures for a longer time. This causes the greatest demand on the system and so lead to the largest power consumption. The large amount of time that the expansion valve spent open may suggest that the system is meeting the limits of its cooling capacity and a further increase in store temperature may overwhelm it.

\section{Conclusion}

In this paper, a commercial refrigeration system validated model is presented for a 2000 sq. ft Riseholme Refrigeration Research Centre. The modelled refrigeration system accurately simulated the operations of the display cases, suction line and compressor pack, with the condenser assumed to return 100\% liquid. Further emphasis has been given to the HT system, due to the HT display cases making up the majority of the display cases in the refrigeration system. Therefore, they have a greater impact on the performance of the system and will be more sensitive to disturbances such as external heat loads. Additionally, the HT system contains a larger number of compressors in comparison with the LTs. Thus, draws more power compared to the LT system, providing greater potential for energy savings. The LT freezers are also likely to be well insulated to ensure products are preserved within them. Thus, indoor store temperature would have little effects on the performance of the system and the frozen products inside.

It is noticed that the trends of the simulation results for the display cases temperatures, expansion valve 
opening degree, suction line pressures and compressor power consumption, all have highly resemblance to the trends of collected data obtained from Riseholme Refrigeration Research Centre. This supports the validation of the developed model.

Investigation into variations of the indoor store temperature has been implemented in order to examine their effects on the refrigeration system performance and power consumption. The store temperature was varied by considering different scenarios in which the AC system could fail or not operate at the desired performance level. Three different scenarios were examined: gradual increase in store temperature caused by an $\mathrm{AC}$ system with reduced performance, sudden increase in store temperature caused by a drastic AC failure and fluctuations in store temperature caused by a faulty AC system.

It is notable that for all three failure types, the product temperature experiences no noticeable fluctuations and remains comfortably within the temperature boundaries between 3 and $1{ }^{\circ} \mathrm{C}$, as the system is able to provide adequate cooling. Moreover, all three failure types also showed that an increased store temperature caused by a failing AC system leads to greater power consumption as the refrigeration system requires greater cooling capacity. Compared to the normal AC operation, the gradual failure consumed further $3 \mathrm{kWh}$ during a 3-h period, yielding a $17.4 \%$ increase. The sudden failure consumed $5.81 \mathrm{kWh}$ of $33.6 \%$ increase. The intermittent fault increased by $0.92 \mathrm{kWh}$ of $5.3 \%$ increase. Additionally, the frequency which the compressors switch on and off increases the level of tear and wear of the compressors. Both gradual and sudden failures of the AC system showed that a sustained increase in temperature leads to greater duty cycles for the expansion valves to increase the amount of refrigerant available. It is found that the sudden failure of the AC system had the greatest impact on the performance of the refrigeration system, this causes the greatest demand on the system and hence leads to higher power consumption. Hence, controlling the operation of the refrigeration and AC systems is vital in providing maximum optimisation of energy savings and maintaining food safety.

\section{Acknowledgements}

The authors would like to thank the School of Engineering and Refrigeration Research Centre at the University of Lincoln for their cooperation and technical support.

\section{Authors' contributions}

The first three authors have contributed to this paper through conducting the relevant literature survey, building the model, examining and analysing the relevant involved parameters and visualising the results. Whilst last author was responsible in supervising and directing the research activities and also drafting and revising the content of this paper. All authors have read and agreed to the published version of the manuscript.

\section{Declarations}

\section{Competing interests}

The authors declare that they have no known competing financial interests or personal relationships that could have appeared to influence the work reported in this paper.

Published online: 28 February 2022

\section{References}

1. Gullpart, J., Curlin, J., \& Clark, E. (2018). Cold chain technology brief: Refrigeration in food production and processing. Paris: International Institute of Refrigeraton IIR.

2. Tassou, S. A., Kolokotroni, M., Gowreesunker, B., Stojceska, V., Azapagic, A., Fryer, P., \& Bakalis, S. (2014). Energy demand and reduction opportunities in the UK food chain. Proceedings of the Institution of Civil Engineers-Energy, 167(3), 162-170. https://doi.org/10.1680/ener.14.00014

3. Olajire, A. A. (2020). The brewing industry and environmental challenges. Journal of Cleaner Production, 256, 102817. https://doi.org/10.1016/j.jclepro.2 012.03 .003

4. Schönberger, C., \& Kostelecky, T. (2011). 125th anniversary review: The role of hops in brewing. Journal of the Institute of Brewing, 117(3), 259-267. https://doi.org/10.1002/j.2050-0416.2011.tb00471.x

5. Briley, G. C. (2003). Refrigeration in large breweries. ASHRAE Journal, 45(2), 49

6. Shafaat, K., Hussain, A., \& Hussain, S. (2013). An overview: Storage of pharmaceutical products. World Journal Pharmaceutical Sciences, 2(5), 24992515 .

7. Kommanaboyina, B., \& Rhodes, C. T. (1999). Trends in stability testing, with emphasis on stability during distribution and storage. Drug Development and Industrial Pharmacy, 25(7), 857-868. https://doi.org/10.1081/DDC-1001 02246

8. Tassou, S., De-Lille, G., \& Lewis, J. (2012). Food transport refrigeration. In Centre for Energy and Built Environment Research, School of Engineering and Design (pp. 1-25). Brunel University.

9. Tassou, S., De-Lille, G., \& Ge, Y. (2009). Food transport refrigerationapproaches to reduce energy consumption and environmental impacts of road transport. Applied Thermal Engineering, 29(8-9), 1467-1477. https://doi. org/10.1016/j.applthermaleng.2008.06.027

10. Smith, A., Watkiss, P., Tweddle, G., McKinnon, A., Browne, M., Hunt, A., Treleven, C., Nash, C., \& Cross, S. (2005). The validity of food miles as an indicator of sustainable development-final report. REPORT ED50254.

11. Hafner, I. A., Gabrielii, C., \& Widell, K. (2019). Refrigeration units in marine vessels: Alternatives to HCFCs and high GWP HFCs. Copenhagen: Nordic Council of Ministers. https://doi.org/10.6027/TN2019-527.

12. Sudheer, K., \& Indira, V. (2007). Post harvest technology of horticultural crops. New Delhi: New India Publishing.

13. Brown, L. G., Ripley, D., Blade, H., Reimann, D., Everstine, K., Nicholas, D., Egan, J., Koktavy, N., Quilliam, D. N., \& EHS-Net Working Group. (2012). Restaurant food cooling practices. Journal of Food Protection, 75(12), 21722178. https://doi.org/10.4315/0362-028X.JFP-12-256

14. Fda, A. (1993). Food code. US Public Health Service. Food and Drug Administration.

15. Suamir, I. N. (2012). Integration of trigeneration and $\mathrm{CO}_{2}$ based refrigeration systems for energy conservation. London: Brunel University School of Engineering and Design PhD Theses.

16. Peixoto, R., Polonara, F., \& Kuijpers, L. (2018). Montreal Protocol on Substances that Deplete the Ozone Layer - 2018 report of the Refrigeration, Air Conditioning and Heat Pumps Technical Options Committee.

17. Briley, G. C. (2004). A history of refrigeration. ASHRAE Journal, 46(11), S31S34.

18. Larsen, L. F. S. (2006). Model based control of refrigeration systems, PhD. Copenhagen: Department of Control Engineering, Aalborg University.

19. Baxter, V. D. (2003). IEA Annex 26: Advanced supermarket refrigeration/heat recovery systems. Oak Ridge: Oak Ridge National Laboratory.

20. Tassou, S., Ge, Y., Hadawey, A., \& Marriott, D. (2011). Energy consumption and conservation in food retailing. Applied Thermal Engineering, 31(2-3), 147-156. https://doi.org/10.1016/j.applthermaleng.2010.08.023

21. Coulomb, D., Dupont, J., \& Pichard, A. (2015). The role of refrigeration in the global economy. In 29th Informatory Note on Refrigeration Technologies; Technical Report. International Institute of Refrigeration. 
22. Shafiei, S. E., Rasmussen, H., \& Stoustrup, J. (2013). Modeling supermarket refrigeration systems for demand-side management. Energies, 6(2), 900-920. https://doi.org/10.3390/en6020900

23. Petersen, L. N., Madsen, H., \& Heerup, C. (2012). Eso2 optimization of supermarket refrigeration systems. Technical University of Denmark.

24. Ge, Y., \& Tassou, S. (2000). Mathematical modelling of supermarket refrigeration systems for design, energy prediction and control. Proceedings of the Institution of Mechanical Engineers, Part A: Journal of Power and Energy, 214(2), 101-114. https://doi.org/10.1243/0957650001538218

25. Sarabia, D., Capraro, F., Larsen, L. F., \& de Prada, C. (2009). Hybrid NMPC of supermarket display cases. Control Engineering Practice, 17(4), 428-441. https://doi.org/10.1016/j.conengprac.2008.09.003

26. Larsen, L. F., Izadi-Zamanabadi, R., \& Wisniewski, R. (2007). Supermarket refrigeration system-benchmark for hybrid system control. 2007 European Control Conference (ECC) (pp. 113-120). Kos, Greece: IEEE.

27. Glavan, M., Gradišar, D., Invitto, S., Humar, I., Juričić, Đ., Pianese, C., \& Vrančić, D. (2016). Cost optimisation of supermarket refrigeration system with hybrid model. Applied Thermal Engineering, 103, 56-66. https://doi.org/10.1016/j.a pplthermaleng.2016.03.177

28. Vinther, K., Rasmussen, H., Izadi-Zamanabadi, R., Stoustrup, J., \& Alleyne, A. G. (2013). A learning based precool algorithm for utilization of foodstuff as thermal energy storage. In 2013 IEEE International Conference on Control Applications (CCA) (pp. 314-321). IEEE.

29. Postnikov, A., Albayati, I., Pearson, S., Bingham, C., Bickerton, R., \& Zolotas, A. (2019). Facilitating static firm frequency response with aggregated networks of commercial food refrigeration systems. Applied Energy, 251, 113357. https://doi.org/10.1016/j.apenergy.2019.113357

30. Saleh, I. M., Postnikov, A., Arsene, C., Zolotas, A. C., Bingham, C., Bickerton, R., \& Pearson, S. (2018). Impact of demand side response on a commercial retail refrigeration system. Energies, $11(2), 371$.

31. Brownbridge, O., Sully, M., Noons, J., \& Albayati, I. M. (2021). Modeling and simulation of a retail commercial refrigeration system. Journal of Thermal Science and Engineering Applications, 13(6), e061028.

32. Danfoss, Refrigeration and air conditioning controls manual: Capacity controller - EKC 531A and 531B 084B8003/084B8004, ed: Danfoss, 2003.

33. Agas. R407F (Genetron Performax LT). Agas. https://Agas.com. Accessed Mar 2020

34. L. Gas. Industrial gases - R407A. Linde Gas. https://Linde-gas.com. Accessed Mar 2020

35. Rac. Is it time to stop using R404A? Racplus.com. https:/www.racplus.com/ features/is-it-time-to-stop-using-r404a-31-01-2011/. Accessed Mar 2020.

36. R. E. S. Limited, Model: ZB45KCE-TFD data, ed. Leicestershire, 2020. Richmonds Earl Shilton Limited, https://Resluk.com.

37. Richmonds Earl Shilton Limited. Model: ZF09K4E-TFD technical data sheet. Richmonds Earl Shilton Limited, https://Resluk.com. https:/www.resluk.com/ images/pdf/compressors/copeland/zf/zf09k4e-tfd.pdf. Accessed Mar 2020.

38. Richmonds Earl Shilton Limited. Model: ZF15K4E-TFD technical data sheet. https://Resluk.com. https:/www.resluk.com/images/pdf/compressors/copela nd/zf/zf15k4e-tfd.pdf. Accessed Mar 2020.

39. Postnikov, A., Zolotas, A., Bingham, C., Saleh, I. M., Arsene, C., Pearson, S., \& Bickerton, R. (2017). Modelling of thermostatically controlled loads to analyse the potential of delivering FFR DSR with a large network of compressor packs. 2017 European Modelling Symposium (EMS) (pp. 163-167). Manchester: IEEE.

40. K. Vinther, Data-driven control of refrigeration systems, Ph. D. thesis, Videnbasen for Aalborg UniversitetVBN, Aalborg, 2014.

41. Lemmon, E. W., Huber, M. L., \& McLinden, M. O. (2002). NIST reference fluid thermodynamic and transport properties-REFPROP. NIST Standard Reference Database, 23, v7.

42. Lemmon, E. W., Huber, M. L., \& McLinden, M. O. (2013). NIST reference fluid thermodynamic and transport properties-REFPROP. NIST Standard Reference Database, 23, v9.1.

43. Bahman, A., Rosario, L., \& Rahman, M. M. (2012). Analysis of energy savings in a supermarket refrigeration/HVAC system. Applied Energy, 98, 11-21. https://doi.org/10.1016/.apenergy.2012.02.043

44. Winterton, R. (1999). Newton's law of cooling. Contemporary Physics, 40(3), 205-212. https://doi.org/10.1080/001075199181549

\section{Publisher's Note}

Springer Nature remains neutral with regard to jurisdictional claims in published maps and institutional affiliations. 